\title{
Phosphonate Decomposition-Induced Polyoxomolybdate Dumbbell-Type Cluster Formation: Structural Analysis, Proton Conduction, and Catalytic Sulfoxide Reduction
}

Eirini Armakola, ${ }^{\ddagger}$ Inés R. Salcedo, ${ }^{\#}$ Montse Bazaga-García, ${ }^{\#}$ Pascual Olivera-Pastor, ${ }^{\#}$ Gellert Mezei, ${ }^{\perp}{ }^{+}$

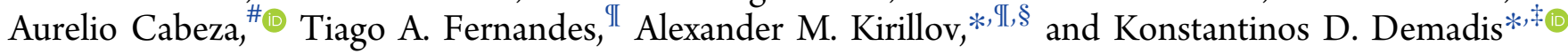

${ }^{\ddagger}$ Crystal Engineering, Growth and Design Laboratory, Department of Chemistry, University of Crete, Voutes Campus, Heraklion, Crete, GR-71003, Greece

\# Departamento de Química Inorgánica, Cristalografía y Mineralogía, Universidad de Málaga, Campus Teatinos s/n, Málaga 29071, Spain

${ }^{\perp}$ Department of Chemistry, Western Michigan University, Kalamazoo, Michigan 49008-5413, United States

${ }^{\mathbb{I}}$ Centro de Química Estrutural, Instituto Superior Técnico, Universidade de Lisboa, Av. Rovisco Pais, 1049-001, Lisbon, Portugal

${ }^{\S}$ Research Institute of Chemistry, Peoples' Friendship University of Russia (RUDN University), 6 Miklukho-Maklaya st., Moscow, 117198, Russian Federation

Supporting Information

ABSTRACT: The reaction of $\mathrm{MoO}_{4}{ }^{2-}$ with a number of phosphonic acids [bis(phosphonomethyl)glycine, $R, S$-hydroxyphosphonoacetic acid, 1-hydroxyethane-1,1-diphosphonic acid, phenylphosphonic acid, aminotris(methylene phosphonic acid), and 1,2ethylenediphosphonic acid] under oxidizing $\left(\mathrm{H}_{2} \mathrm{O}_{2}\right)$ hydrothermal conditions at low $\mathrm{pH}$ leads to rupture of the $\mathrm{P}-\mathrm{C}$ bond, release of orthophosphate ions, and generation of the octanuclear, phosphate-bridged, polyoxometalate molybdenum cluster $\left(\mathrm{NH}_{4}\right)_{5}\left[\mathrm{Mo}_{8}(\mathrm{OH})_{2} \mathrm{O}_{24}\left(\mu_{8}-\mathrm{PO}_{4}\right)\right]\left(\mathrm{H}_{2} \mathrm{O}\right)_{2}$ (POMPhos). This cluster has been fully characterized and its structure determined. It was studied as a proton conductor, giving moderate values of $\sigma=2.13 \times 10^{-5} \mathrm{~S} \cdot \mathrm{cm}^{-1}\left(25^{\circ} \mathrm{C}\right)$ and $1.17 \times 10^{-4} \mathrm{~S} \cdot \mathrm{cm}^{-1}\left(80{ }^{\circ} \mathrm{C}\right)$ at $95 \%$

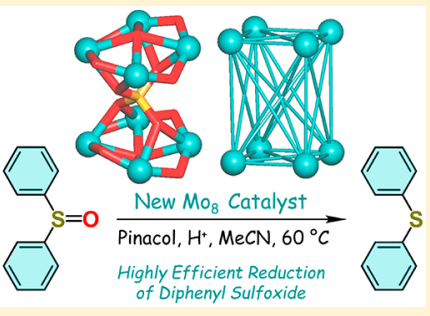
relative humidity, with $E_{\mathrm{a}}=0.27 \mathrm{eV}$. The POMPhos cluster was then thermally treated at $310{ }^{\circ} \mathrm{C}$, yielding $\left(\mathrm{NH}_{4}\right)_{2.6}\left(\mathrm{H}_{3} \mathrm{O}\right)_{0.4}\left(\mathrm{PO}_{4} \mathrm{Mo}_{12} \mathrm{O}_{36}\right)$ together with an amorphous impurity containing phosphate and molybdenum oxide. This product was also studied for its proton conductivity properties, giving rise to an impressively high value of $\sigma=2.43 \times 10^{-3} \mathrm{~S}$. $\mathrm{cm}^{-1}\left(25{ }^{\circ} \mathrm{C}\right)$ and $6.67 \times 10^{-3} \mathrm{~S} \cdot \mathrm{cm}^{-1}\left(80^{\circ} \mathrm{C}\right)$ at $95 \%$ relative humidity, 2 orders of magnitude higher than those corresponding to the "as-synthesized" solid. The utilization of POMPhos in catalytic reduction of different sulfoxides was also evaluated. POMPhos acts as an efficient homogeneous catalyst for the reduction of diphenyl sulfoxide to diphenyl sulfide, as a model reaction. Pinacol was used as a low-cost, environmentally friendly, and highly efficient reducing agent. The effects of different reaction parameters were investigated, namely the type of solvent and reducing agent, presence of acid promoter, reaction time and temperature, loading of catalyst and pinacol, allowing to achieve up to 84-99\% yields of sulfide products under optimized conditions. Substrate scope was tested on the examples of diaryl, alkylaryl, dibenzyl, and dialkyl sulfoxides and excellent product yields were obtained.

\section{INTRODUCTION}

Metal phosphonate-based materials have gained attention over the last couple decades for several reasons. ${ }^{1}$ The idiosyncrasies of the R-PO $(\mathrm{OH})_{2}$ phosphonate linker include a tetrahedral $\mathrm{P}(\mathrm{V})$, a doubly deprotonatable moiety, ${ }^{2}$ a thermally and enzymatically resistant $\mathrm{P}-\mathrm{C}$ bond, ${ }^{3}$ and high affinity for metal ions (from monovalent to polyvalent), ${ }^{4}$ along with strong bridging tendency. ${ }^{5}$

One of the main structural differences between phosphonates and phosphate esters is the presence of a $\mathrm{P}-\mathrm{C}$ bond in the former and a $\mathrm{P}-\mathrm{O}-\mathrm{C}$ bond in the latter. ${ }^{6}$ This renders phosphonates resistant to hydrolytic, ${ }^{7,8}$ thermal, ${ }^{9,10}$ or enzymatic processes. ${ }^{11,12}$ However, there are some examples in metal phosphonate chemistry where serendipitous $\mathrm{P}-\mathrm{C}$ bond scission has been observed, thus generating a secondary ligand in situ, leading to novel products. Occasionally, such in situ ligand generation results in new metal phosphonate structures, unattainable by other, conventional synthetic methods. Free etidronic acid $\left[\mathrm{CH}_{3} \mathrm{C}(\mathrm{OH})\left(\mathrm{PO}_{3} \mathrm{H}_{2}\right)_{2}\right.$, (1hydroxyethylidene)-1,1-bisphosphonic acid] was found to undergo a remarkably facile cleavage of the $\mathrm{P}-\mathrm{C}$ bond under mildly basic conditions. ${ }^{13}$ Stock et al. used the aromatic phosphonocarboxylic acid $\left(\mathrm{H}_{2} \mathrm{O}_{3} \mathrm{PCH}_{2}\right)_{2} \mathrm{NCH}_{2} \mathrm{C}_{6} \mathrm{H}_{4} \mathrm{COOH}$ in the hydrothermal synthesis of new $\mathrm{Ba}$ phosphonates. Its decomposition (by removal of the $-\mathrm{CH}_{2} \mathrm{C}_{6} \mathrm{H}_{4} \mathrm{COOH}$ "arm")

Received: May 11, 2019

Published: August 12, 2019 
led to the first open-framework barium phosphonate $\left[\mathrm{Ba}_{3}\left(\mathrm{O}_{3} \mathrm{PCH}_{2} \mathrm{NH}_{2} \mathrm{CH}_{2} \mathrm{PO}_{3}\right)_{2}\left(\mathrm{H}_{2} \mathrm{O}\right)_{4}\right] \cdot 3 \mathrm{H}_{2} \mathrm{O} .{ }^{14}$ Hydrothermal reaction of 1-amino-1-phenylmethane-1,1-diphosphonic acid $\left(\mathrm{APhMDPH}_{4}\right), \mathrm{ZnO}$ and 2,2'-bipy causes a self-condensation process to create a bicyclic tetraphosphonate derivative. ${ }^{15,16}$

The deoxygenation of sulfoxides is an important process with significance in a variety of synthetic transformations and biological processes. ${ }^{17}$ There is a continuous interest in developing new and sustainable protocols for sulfoxide deoxygenation. ${ }^{18-23}$ In nature, there are several molybdenum-based enzymes (e.g., dimethyl sulfoxide, methionine sulfoxide and biotin sulfoxide reductases) that can efficiently perform sulfoxide deoxygenation. ${ }^{24,25}$ Synthetic high-valence dioxomolybdenum(VI) derivatives are also known to catalyze various oxygen-transfer processes using sulfoxides as substrates to form sulfides, phosphines, or olefins. Some catalytic examples described in the literature include the silane/ $\mathrm{MoO}_{2} \mathrm{Cl}_{2}$ or borane $/ \mathrm{MoO}_{2} \mathrm{Cl}_{2}$ systems toward the hydrosilylation of aldehydes and ketones to silyl ethers and for the reduction of imines, amides, esters, sulfoxides, and pyridine $\mathrm{N}$ oxides to the corresponding amines, alcohols, sulfides, and pyridines. $^{21,23,26,27}$ Considerable attention was also focused on the development of cleaner processes to avoid the use of hazardous reducing agents and/or systems containing $\mathrm{H}_{2}$. Pinacol (2,3-dimethyl-2,3-butanediol) represents a particularly attractive reducing agent in Mo-based systems, due to its lowcost and biodegradability. ${ }^{28-30}$ Considering the abovementioned catalytic potential of Mo-based systems, one of the aims of the present study consisted in probing the catalytic activity of the obtained $\mathrm{Mo}_{8}$ derivative toward the reduction of diphenyl sulfoxide to diphenyl sulfide as a model reaction. On the other hand, by their well-defined structural characteristics and the presence of proton-donating sites, polyoxometalates (POMs) are also worthy to investigate for their protonconducting properties. ${ }^{31-34}$

In this paper, we report the serendipitous synthesis of the octanuclear, phosphate-bridged, polyoxometalate molybdenum cluster $\left(\mathrm{NH}_{4}\right)_{5}\left[\mathrm{Mo}_{8}(\mathrm{OH})_{2} \mathrm{O}_{24}\left(\mu_{8}-\mathrm{PO}_{4}\right)\right]\left(\mathrm{H}_{2} \mathrm{O}\right)_{2}$ (POMPhos), in which the $\mathrm{PO}_{4}{ }^{3-}$ bridge has been generated in situ by oxidative decomposition of phosphonate ligands. The synthesis, physicochemical and structural characterization, as well as proton conductivity properties are reported. Finally, the catalytic application of this cluster in the reduction of diphenyl sulfoxide (model substrate) and other alkylaryl, dibenzyl, and dialkyl sulfoxides to the corresponding sulfide products was shown.

\section{EXPERIMENTAL SECTION}

Reagents and Equipment. All chemicals (metal salts, phosphonic acid ligands, cycloalkanes, reagents for catalytic tests, and solvents) were purchased commercially and were used as received without further purification. Ion exchange column-deionized (DI) water was used for the syntheses. Stock aqueous solutions of $\mathrm{NaOH}$ and $\mathrm{HCl}(1.0$ and $0.1 \mathrm{M})$ were used for $\mathrm{pH}$ adjustment during the synthesis. FTIR spectra were obtained on a Shimadzu IRAffinity-1S apparatus using ATR ZnSe Performance Crystal Plate accessory.

Synthesis of the Ligand BPMGLY. The ligand BPMGLY was prepared according to a well-established Mannich-type phosphonomethylation process starting with the amino acid glycine, following published procedures. ${ }^{35}$

Synthesis of $\left(\mathrm{NH}_{4}\right)_{5}\left[\mathrm{Mo}_{8}(\mathrm{OH})_{2} \mathrm{O}_{24}\left(\mu_{8}-\mathrm{PO}_{4}\right)\right]\left(\mathrm{H}_{2} \mathrm{O}\right)_{2}$ (POMPhos). The initial synthesis of the cluster POMPhos involved the use of the aminomethylenephosphonate BPMGLY. This synthetic procedure is described below. However, BPMGLY can be replaced with the phosphonates HPAA, HEDP, PPA, or AMP (in appropriate stoichiometric amounts) with the same outcome. POMPhos was synthesized under hydrothermal conditions, as follows. A mixture of $\mathrm{Na}_{2} \mathrm{MoO}_{4} \cdot 2 \mathrm{H}_{2} \mathrm{O}$ (1.73 g, $7.15 \mathrm{mmol}$ ) and BPMGLY (0.158 g, 0.6 $\mathrm{mmol}$ ) were dissolved in $15 \mathrm{~mL}$ of DI water. Then, to that solution was added $1.7 \mathrm{~mL}$ of $\mathrm{HNO}_{3}$ and $2 \mathrm{~mL}$ of $\mathrm{H}_{2} \mathrm{O}_{2}(30 \%)$. The $\mathrm{pH}$ was adjusted to 4.2 with a $25 \% \mathrm{NH}_{3}$ solution. The final yellow solution was placed into a sealed custom-made bomb $(25 \mathrm{~mL}$ volume $)$ equipped with a Teflon liner. The bomb was placed in an oven and then heated at $120^{\circ} \mathrm{C}$ for 4 days. After the solution was slowly cooled to room temperature, colorless crystals formed, which were isolated by filtration, washed with small amounts of DI water, and dried in air. Yield: $0.513 \mathrm{~g}$ ( $36 \%$ based on BPMGLY). Yields obtained by use of other phosphonic acids: 17\% (based on AMP), 14\% (based on HPAA), 9\% (based on HEDP), 3\% (based on PPA), 6\% (based on EDPA). Anal. Calcd for $\left(\mathrm{NH}_{4}\right)_{5}\left[\mathrm{Mo}_{8}(\mathrm{OH})_{2} \mathrm{O}_{24}\left(\mathrm{PO}_{4}\right)\right]\left(\mathrm{H}_{2} \mathrm{O}\right)_{2}: \mathrm{H}$, 1.86; N, 4.98. Found: H, 1.99; N, 5.11. FTIR (ATR), $\mathrm{cm}^{-1}: 3555(\mathrm{w})$, 3491 (w), 3182 (br), 1637 (w), 1609 (w), 1396 (vs), 1038 (s), 1017(s), 941(s), 900 (s), 711 (vs), 673 (vs). The phosphonic acid ligands used in the syntheses are listed in Figure 1. After identification

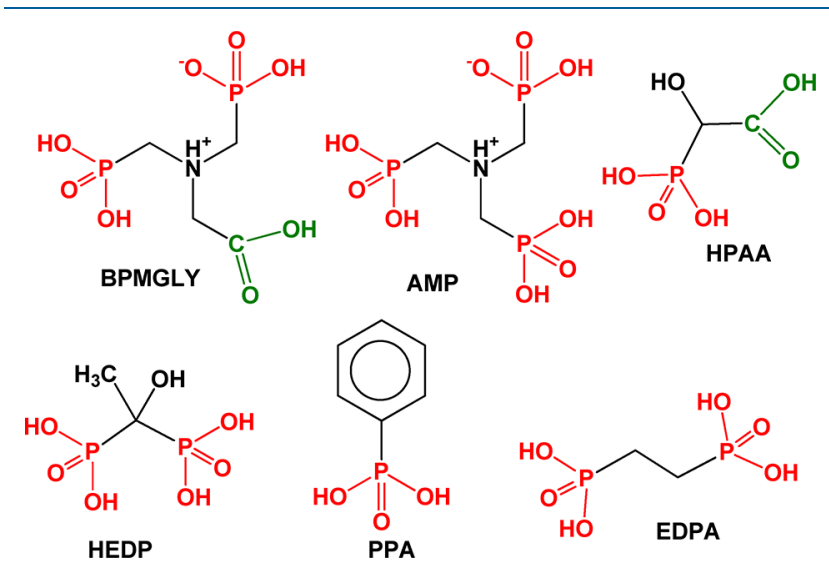

Figure 1. Schematic structures of the phosphonic acid ligands used for the synthesis of POMPhos. Phosphonate moieties are highlighted in red; carboxylate, in green.

of the structure of the final product, efforts were put forth to perform the synthesis by omitting the phosphonic acid component, but providing orthophosphate ions. No isolable product was formed. Finally, $\mathrm{H}_{3} \mathrm{PO}_{3}$ (phosphorus acid) was used in the place of orthophosphate, which led to isolation of POMPhos in $\sim 25 \%$ yield.

\section{INSTRUMENTATION}

Thermogravimetric Analysis (TGA). Thermogravimetric analysis (TGA) data were recorded on an SDT-Q600 analyzer from TA Instruments. The temperature varied from room temperature to 900 ${ }^{\circ} \mathrm{C}$ at a heating rate of $10{ }^{\circ} \mathrm{C} \cdot \mathrm{min}^{-1}$. Measurements were carried out on samples in open platinum crucibles under a flow of air.

Single Crystal X-ray Determination. X-ray diffraction data were collected at room temperature from a single-crystal mounted atop a glass fiber with cyanoacrylate glue, with a Bruker SMART APEX II diffractometer using graphite-monochromated Mo $\mathrm{K} \alpha$ radiation. The structure was solved by employing SHELXTL direct methods and refined by full-matrix least-squares on $F^{2}$, using the APEX2 software package. $^{36}$ All non-H atoms were refined with independent anisotropic displacement parameters. Hydrogen atoms for the complex's $\mathrm{OH}$ units, the lattice $\mathrm{H}_{2} \mathrm{O}$ molecules, and the $\mathrm{NH}_{4}{ }^{+}$ counterions were located from the Fourier difference density map and were refined using a riding model with $\mathrm{O}-\mathrm{H}$ and $\mathrm{N}-\mathrm{H}$ distance restraints. Crystallographic details are summarized in Table 1.

Powder X-ray Diffraction. Laboratory X-ray powder diffraction (XRPD) patterns were collected on a PANanalytical EMPYREAN diffractometer, in Bragg-Brentano reflection configuration by using $\mathrm{Cu} \mathrm{K} \alpha_{1,2}$ radiation and a PIXcel detector. X-ray patterns were 
Table 1. Selected Crystallographic Data for POMPhos

\begin{tabular}{|c|c|}
\hline compound & POMPhos \\
\hline empirical formula & $\mathrm{H}_{26} \mathrm{Mo}_{8} \mathrm{~N}_{5} \mathrm{O}_{32} \mathrm{P}$ \\
\hline $\mathrm{fw}\left(\mathrm{g} \mathrm{mol}^{-1}\right)$ & 1406.75 \\
\hline temp $(\mathrm{K})$ & $296(2)$ \\
\hline space group & $\mathrm{Cmcm}$ \\
\hline$\lambda(\AA)$ & 0.71073 \\
\hline$a(\AA)$ & $8.5171(1)$ \\
\hline$b(\AA)$ & $22.8040(3)$ \\
\hline$c(\AA)$ & $15.4949(2)$ \\
\hline$\alpha(\operatorname{deg})$ & 90 \\
\hline$\beta(\operatorname{deg})$ & 90 \\
\hline$\gamma(\mathrm{deg})$ & 90 \\
\hline$V\left(\AA^{3}\right)$ & $3009.48(7)$ \\
\hline crystal size $(\mathrm{mm})$ & $0.37 \times 0.30 \times 0.25$ \\
\hline$Z$ & 4 \\
\hline$\rho_{\text {calc }}\left(\mathrm{g} \cdot \mathrm{cm}^{-3}\right)$ & 3.105 \\
\hline $2 \theta$ range $(\mathrm{deg})$ & $1.79-30.55$ \\
\hline data/restrains/parameters & $37905 / 29 / 152$ \\
\hline no. of reflections & 2530 \\
\hline independent reflections $[I>2 \sigma(I)]$ & 2393 \\
\hline GoF, $F^{2}$ & 1.033 \\
\hline$R$ factor $[I>2 \sigma(I)]$ & ${ }^{a} R 1=0.0228, w R 2=0.1108$ \\
\hline$R$ factor (all data) & ${ }^{a} R 1=0.0243,{ }^{a} w R 2=0.1149$ \\
\hline maximum peak/hole $\left(e \cdot \AA^{-3}\right)$ & $0.437 /-2.042$ \\
\hline CCDC reference code & 1900362 \\
\hline \multicolumn{2}{|c|}{${ }^{a} \mathrm{R}_{1}(\mathrm{~F})=\Sigma\left\|\mathrm{F}_{\mathrm{o}}|-| \mathrm{F}_{\mathrm{c}}\right\| / \Sigma\left|\mathrm{F}_{\mathrm{o}}\right| ; \mathrm{wR}_{2}\left(\mathrm{~F}^{2}\right)=\left[\Sigma \mathrm{w}\left(\mathrm{F}_{\mathrm{o}}^{2}-\mathrm{F}_{\mathrm{c}}^{2}\right)^{2} / \Sigma \mathrm{F}^{4}\right]^{1 / 2}$} \\
\hline
\end{tabular}

recorded between 4 and $70^{\circ}(2 \theta)$, with a $0.026^{\circ}$ step size and an equivalent counting time of $\sim 24 \mathrm{~s} /$ step. The thermodiffractometric study of the sample as well as the Rietveld analysis were carried out on a PANalytical X'Pert Pro diffractometer, in Bragg-Brentano configuration, using a $\mathrm{Ge}(111)$ primary monochromator $\left(\mathrm{Cu} \mathrm{K} \alpha_{1}\right)$ and an X'Celerator detector. Data at different temperatures between 30 and $500{ }^{\circ} \mathrm{C}$ were collected using an Anton Paar TTK450 Camera, under static air. A delay time of $15 \mathrm{~min}$ to ensure thermal stabilization was applied at each temperature. XRPD patterns were recorded between 4 and $70^{\circ}$ in $2 \theta$, with a step size of $0.017^{\circ}$ and an equivalent counting time of $\sim 59 \mathrm{~s} / \mathrm{step}$. In order to estimate the overall amorphous content of the compound obtained at $310{ }^{\circ} \mathrm{C}$, a sample containing $22 \mathrm{wt} \%$ of $\alpha-\mathrm{Al}_{2} \mathrm{O}_{3}$ as internal standard was prepared and analyzed by the Rietveld method. ${ }^{37,38}$ Its XRPD pattern was registered in the region $6-80^{\circ}$ in $2 \theta$, with a step size of $0.017^{\circ}$ and an equivalent counting time of $\sim 400 \mathrm{~s} / \mathrm{step}$. The refinement was done using the crystal structure of $\left(\mathrm{NH}_{4}\right)_{2.6}\left(\mathrm{H}_{3} \mathrm{O}\right)_{0.4}\left(\mathrm{PO}_{4} \mathrm{Mo}_{12} \mathrm{O}_{36}\right)$ as starting model $^{39}$ and the GSAS program. ${ }^{78}$

X-ray Photoelectron Spectroscopy. XPS measurement was carried out by using a PHI VersaProbe II instrument with monochromatic $\mathrm{Al} \mathrm{K} \alpha \mathrm{X}$-ray line $(1486.6 \mathrm{eV})$ at $53.6 \mathrm{~W}$ and a beam diameter of $200.0 \mu \mathrm{m}$.

Solid-State NMR. ${ }^{31} \mathrm{P}$ MAS NMR (magic angle spinning nuclear magnetic resonance) spectra were recorded at room temperature in an AVANCEIII HD 600 (Bruker AXS) spectrometer using a triple resonance CP-MAS probe of $3.2 \mathrm{~mm}$ at a spinning rate of $15 \mathrm{kHz}$. The magnetic field was $14.1 \mathrm{~T}$, corresponding to a ${ }^{31} \mathrm{P}$ resonance frequency of $242.92 \mathrm{MHz}$. The ${ }^{31} \mathrm{P}$ chemical shifts are referenced to ADP. ${ }^{31} \mathrm{P}$ MAS NMR spectra were recorded with a length pulse of 4 $\mu$ s and 5-s delay with ${ }^{1} \mathrm{H}$ decoupling $\left({ }^{31} \mathrm{P} \mathrm{Hpdec}\right.$ with spinal decoupling sequence 64 for $\mathrm{P}$ ) and summing up 64 scans.

Proton Conductivity Measurements. Impedance data were registered on cylindrical pellets (diameter $\sim 5 \mathrm{~mm}$ and thickness $\sim 1$ $\mathrm{mm}$ ) which were pressed between porous $\mathrm{C}$ electrodes (Sigracet, GDL $10 \mathrm{BB}$, no Pt). The sample cell was placed inside a temperature and humidity-controlled chamber (Espec SH-222). AC impedance data were collected using a HP4284A impedance analyzer over the frequency range of $20 \mathrm{~Hz}$ to $1 \mathrm{MHz}$ with an applied voltage of $1 \mathrm{~V}$ for the "as-synthesized" compound and $0.5 \mathrm{~V}$ for the solid obtained by heating at $310{ }^{\circ} \mathrm{C}$. To equilibrate water content, pellets were first preheated $\left(0.2{ }^{\circ} \mathrm{C} / \mathrm{min}\right)$ from 25 to $80{ }^{\circ} \mathrm{C}$ and $95 \% \mathrm{RH}$. Impedance spectra were recorded on cooling using a stabilization time of $5 \mathrm{~h}$ for each temperature $\left(80,70,60,50,40,30\right.$, and $\left.25{ }^{\circ} \mathrm{C}\right)$. Water condensation on sample was avoided by reducing first the relative humidity before decreasing temperature. All measurements were electronically controlled by the winDETA package of programs. ${ }^{40}$ For the POMPhos sample, the total pellet resistance $\left(R_{\mathrm{T}}\right)$ values were obtained from the interception of the spike and/or the arc (low frequency end) on the $Z^{\prime}$ axis. In the case of the $310{ }^{\circ} \mathrm{C}$ calcined material, $R_{\mathrm{T}}$ values were obtained at high frequency $(1 \mathrm{MHz})$.

Topological Analysis. The topological analysis and classification of the discrete $0 \mathrm{D} \mathrm{Mo}_{8}$ cluster was carried out with Topos software ${ }^{41}$ and by using a method developed for the topological analysis of high nuclearity coordination clusters. ${ }^{42,43}$

Catalytic Reduction of Diphenyl Sulfoxide. The catalytic reactions were typically performed in thermostated glass reactors equipped with a reflux condenser under vigorous stirring at $60{ }^{\circ} \mathrm{C}$, in air atmosphere, and using different solvents $(\mathrm{MeCN}$, toluene, THF, or other solvent; up to $5 \mathrm{~mL}$ total volume). In a typical test, POMPhos catalyst $(5 \mu \mathrm{mol})$ and the GC internal standard (cyclooctane, 13.5 $\mu \mathrm{L}$ ) were introduced into a selected solvent, followed by the addition of $\mathrm{HCl}$ as an acid promoter (typically $0.1 \mathrm{mmol}$ ), diphenyl sulfoxide $(0.25 \mathrm{mmol})$ as a model substrate, and pinacol $(0.25 \mathrm{mmol})$ as a reducing agent. The reaction progress was monitored by withdrawing small aliquots of the reaction mixtures after different periods of time. The samples were analyzed by GC using cyclooctane as an internal standard. Agilent Technologies 7820A series gas chromatograph ( $\mathrm{He}$ as carrier gas) equipped with the FID detector and the BP5/SGE (30 $\mathrm{m} \times 0.22 \mathrm{~mm} \times 0.25 \mu \mathrm{m})$ or BP20/Agilent $(30 \mathrm{~m} \times 0.22 \mathrm{~mm} \times 0.25$ $\mu \mathrm{m})$ capillary column. GC peak assignment was made by comparison with chromatograms of authentic samples. Blank tests confirmed that the reduction of diphenyl sulfoxide does not occur in the absence of a molybdenum catalyst in different solvents $(<0.5 \%$ yields). Screening of several reaction parameters was performed aiming at the investigation of the effects of catalyst loading, temperature, solvent, reducing agent, and the presence of an acid promoter $(\mathrm{HCl})$. The catalytic reduction of other substrates (methyl phenyl sulfoxide, dibenzyl sulfoxide, and dimethyl sulfoxide) was performed as described above for diphenyl sulfoxide.

\section{RESULTS AND DISCUSSION}

Synthesis and Characterization of the Catalyst POMPhos. Our initial synthetic attempts were targeted toward the synthesis of molybdenum phosphonates, inspired by the few literature examples. ${ }^{44-57}$ Molybdenum phosphonate chemistry has been explored to a relatively limited extent, and the main characteristic of such systems is the unpredictability of the final products, most of which are formed serendipitously. In the molybdate/phosphonate systems explored herein, no molybdenum phosphonate product was isolated. Instead, every phosphonate tested degraded under the oxidizing conditions to generate orthophosphate ions which were found in a $\mu_{8^{-}}$ bridging mode, connecting eight $\mathrm{Mo}(\mathrm{VI})$ centers, four from each half of the cluster (see Figure S1 in the Supporting Information). The failure of synthetic efforts involving orthophosphate (instead of phosphonate) may imply that initial coordination of the phosphonate ligand to $\mathrm{Mo}(\mathrm{VI})$ is a necessary step in the process. Phosphonate sensitivity to oxidizers is well-known. ${ }^{7,8}$ Studies have proven the production of orthophosphate, along with other organic fragments (depending on the degrading phosphonate), such as iminodiphosphonate, formate, $\mathrm{N}$-formyl iminodi(methylene)phosphonate, ${ }^{58,59}$ pyruvate, phosphonopyruvate, acetate, acetaldehyde, ${ }^{60}$ aminomethylphosphonic acid, glyphosate, ${ }^{61}$ and others. It has also been reported that the presence of metal 
ions enhances phosphonate degradation. ${ }^{62}$ Hence, it is not surprising that all phosphonates evaluated herein as potential ligands degrade to produce orthophosphate. We have attempted to identify reaction byproducts by ${ }^{31} \mathrm{P}$ NMR spectroscopy, but each system produced more than 10 phosphorus signals, therefore this effort was abandoned.

The purity of compound POMPhos was evaluated by XRPD, revealing a good agreement between the simulated (from the single-crystal data) and the experimental (obtained for the polycrystalline sample) X-ray diffraction patterns (Figure S2, Supporting Information). The difference observed in the intensity of some diffraction peaks can be due to preferred orientation effects. In addition, the full decomposition of the organic ligand was confirmed by ${ }^{31} \mathrm{P}$ CP-MAS NMR. The spectrum of the sample (Figure S3, Supporting Information) contains only one signal at $7.6 \mathrm{ppm}$ that corresponds to a unique phosphorus environment, as found in the single crystal of POMPhos, and in accordance with the report of $\mathrm{Bai}$ et al. for the anhydrous $\mathrm{Na}_{7} \mathrm{PMo}_{8} \mathrm{O}_{30}$ compound. ${ }^{63}$

Structural Description of the POMPhos Cluster. The compound POMPhos crystallizes in the orthorhombic $(\mathrm{Cmcm})$ crystal system, with the $\left[\left\{\mathrm{Mo}_{4}\left(\mu_{4}-\mathrm{OH}\right)(\mu\right.\right.$ $\left.\left.\mathrm{O})_{4} \mathrm{O}_{8}\right\}_{2}\left(\mathrm{PO}_{4}\right)\right]^{5-}$ unit centered around a special position (intersection of two mirror planes). The $\mathrm{Mo}(\mathrm{VI})$ ions define

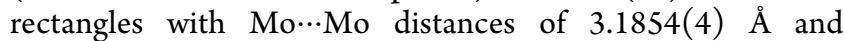
3.3339(3) $\AA$ (for Mo1), and 3.1862(4) $\AA$ and 3.3413(6) $\AA$ (for Mo2). Each rectangle is capped by a $\mu_{4}-\mathrm{OH}$ unit and has a $\mu_{2}-\mathrm{O}$ unit on each of its sides (Figure 2). Each Mo corner has

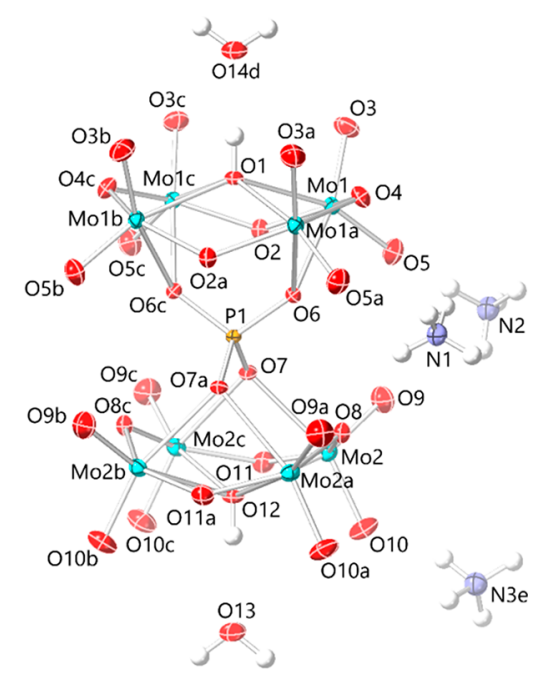

Figure 2. Thermal ellipsoid plot (50\% probability) of POMPhos. Symmetry operators: (a) $x, y,-z+{ }^{1} / 2$; (b) $-x, y,-z+1 / 2$; (c) $-x, y$, $z$; (d) $-x+1, y-1, z$; (e) $x-1 / 2, y-1 / 2,-z+1 / 2$.

two additional terminal oxo ligands, giving rise to a distorted octahedral coordination sphere around the Mo centers (Table S1, Supporting Information). Two $\left\{\mathrm{Mo}_{4}\left(\mu_{4}-\mathrm{OH}\right)\left(\mu_{2}-\mathrm{O}\right)_{4} \mathrm{O}_{8}\right\}$ rectangles are bridged by a phosphate trianion $\left(\mu_{8}-\mathrm{PO}_{4}{ }^{3-}\right)$, so that each $\mathrm{O}$ atom of the latter forms a $\mu_{2}$-bridge between two adjacent Mo atoms of the individual rectangles. The two $\mu_{4}$ $\mathrm{OH}$ units of the complex (O1 and $\mathrm{O} 12$ ) form $\mathrm{H}$-bonds to water molecules centered above and below the complex (O13 and O14), with crystallographically imposed donor-Hacceptor angles of $180^{\circ}$ (Table S3, Supporting Information). The $\mathrm{NH}_{4}{ }^{+}$counterions have their $\mathrm{N}$ atoms located on special positions (with occupancies of 0.25 or 0.50 ) and form $\mathrm{H}$ bonds with the $\mathrm{O}$ atoms of the Mo cluster (Figure 3). However, this species does not interact with the uncoordinated water molecules and thus efficient hydrogen transport pathways are limited in this structure.

Topological Analysis. To perform the topological classification of the discrete OD POMPhos cluster (Figure $4 a, b)$, we used a method developed for the topological analysis of high nuclearity coordination clusters. ${ }^{41-43}$ First, a simplified structure of the $\left[\left\{\mathrm{Mo}_{4}\left(\mu_{4}-\mathrm{O}\right)(\mu-\mathrm{O})_{4}\right\}_{2}\left(\mu_{8}-\mathrm{PO}_{4}\right)\right]$ core (Figure $4 \mathrm{c})$ was generated by removing all terminal oxo ligands and hydrogen atoms from the $\mu_{4}-\mathrm{OH}$ groups. Then, a graph of the $\mathrm{Mo}_{8}$ skeleton (Figure 4d) was obtained by (1) transforming all $\mu$-O atoms into metal-metal edges, (2) contracting the $\mu_{4}$ $\mathrm{O}(\mathrm{H})$ ligands to the metal nodes along with the generation of the respective graph edges, and (3) contracting the central $\mu_{8}$ $\mathrm{PO}_{4}{ }^{3-}$ spacer into graph edges. As a result, the obtained $\mathrm{Mo}_{8}$ skeleton can be considered as two $\mathrm{Mo}_{4}$ motifs, wherein each metal node is interconnected with all the other seven nodes. Globally, the skeleton is assembled from the eight topologically equivalent Mo nodes, which are 7-connected and arranged into a uninodal net with the 7M8-1 topology and point symbol of $\left(3^{21}\right)$.

This topology is described by the $N D k-m$ classification, wherein $N$ is a set of coordination numbers of the nodes $(N=$ 7 for 7 -connected nodes), $\mathrm{D}$ is dimensionality ( $\mathrm{D}=M$ for discrete $0 \mathrm{D}$ molecular clusters), $k$ is a number of metal atoms in the cluster $(k=8)$, and $m$ is a classification number to distinguish topologically distinct clusters with equal NDk parameters. $^{41-43}$

Thermal Behavior. Thermogravimetric analysis (Figure 5) indicates that no weight loss occurs up to $200{ }^{\circ} \mathrm{C}$. The first weight loss in the temperature range $200-315^{\circ} \mathrm{C}$ is attributed to a partial elimination of ammonia and water, occurring concomitantly with a structural transformation, as revealed by thermodiffraction (Figure 6). A second stage of weight loss is observed in the TGA curve between 400 and $460{ }^{\circ} \mathrm{C}$, assigned to decomposition of the heteropolyanion into $\mathrm{MoO}_{3}$ (ICSD\# 152313) as the unique crystalline phase.

The new crystalline phase, appearing clearly at $310{ }^{\circ} \mathrm{C}$ in the thermodiffraction patterns, corresponds to the compound $\left(\mathrm{NH}_{4}\right)_{2.6}\left(\mathrm{H}_{3} \mathrm{O}\right)_{0.4}\left(\mathrm{PO}_{4} \mathrm{Mo}_{12} \mathrm{O}_{36}\right)$ (ICSD\# 000212), which remains stable up to $400{ }^{\circ} \mathrm{C}$. Further chemical, ${ }^{31} \mathrm{P}$ MAS NMR (Figure S3), XRD (Figure S4), and XPS (Figure S5) analysis of a sample heated at $310^{\circ} \mathrm{C}$ for $2 \mathrm{~h}$ confirmed that this phase is present together with an amorphous impurity containing phosphate and molybdenum oxide. Three different phosphorus environments were detected by ${ }^{31} \mathrm{P}$ MAS NMR. The main contribution arises from the crystalline phase, at $-4.36 \mathrm{ppm}$, which is characteristic of $\left[\mathrm{PO}_{4} \mathrm{Mo}_{12} \mathrm{O}_{36}\right]^{3-}$ ions. ${ }^{64}$ There are two additional small and broad signals at 4.35 and $1.30 \mathrm{ppm}$, indicative of the presence of other unidentified environments of phosphorus as well as are consistent with the formation of partially hydrated forms of polyoxometalates, as confirmed by TG analysis (Figure S6). ${ }^{65}$ The amorphous phase was estimated to be $\sim 30 \%$ by Rietveld analysis. The Mo 3d XPS signal of the heated sample matches with Mo(VI) being the major species $(233.09 \mathrm{eV})$, and only traces of $\mathrm{Mo}(\mathrm{V})$ were detected $(236.22 \mathrm{eV})$.

Proton Conductivity Studies. Subtle changes in the hydration degree for the POMPhos and the $310^{\circ} \mathrm{C}$ calcined materials were observed by thermogravimentric analysis. POMPhos is partially dehydrated (Figure S6) after impedance 


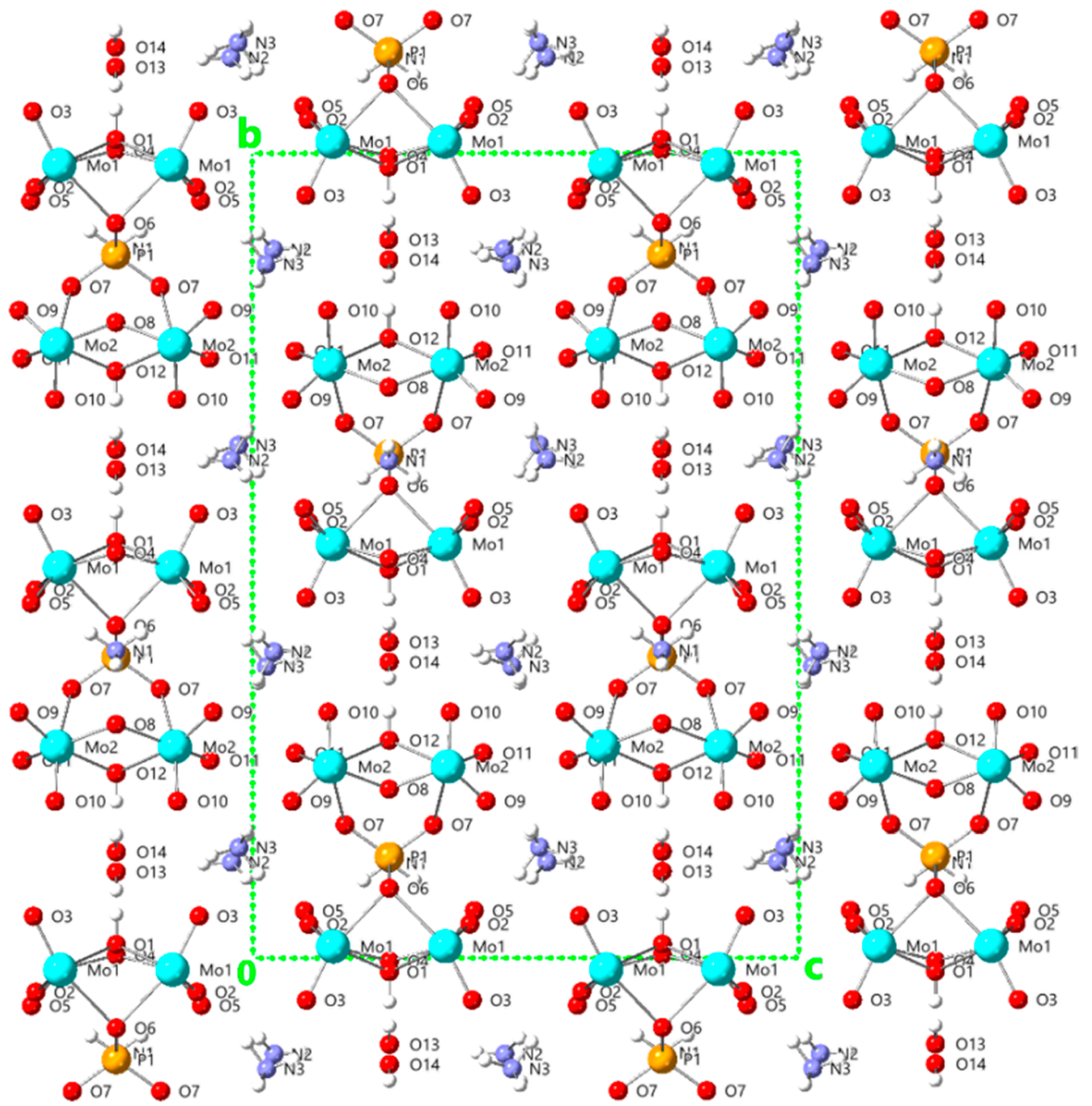

Figure 3. Packing diagram of POMPhos viewed along the $a$-axis.

measurements when compared to the "as-synthesized" POMPhos material. However, the opposite happens for the calcined sample, although the XRDP patterns do not show structural changes (Figure S7). This is indicative of water adsorption by the amorphous phase, which may contribute to total proton conductivity.

From the Nyquist plots for POMPhos and the $310{ }^{\circ} \mathrm{C}$ calcined material (Figure S8), the conductivity values were determined at each temperature and 95\% RH. The Arrhenius plots are displayed in Figure 7. The activation energies, 0.27 and $0.17 \mathrm{eV}$ respectively, fall quite below the limit for a Grotthuss transfer mechanism, ${ }^{66}$ and thus no vehicular transfer mechanism is expected for these materials.

The conductivity values for the calcined material, at 25 and $80{ }^{\circ} \mathrm{C}$, are $2.43 \times 10^{-3} \mathrm{~S} \cdot \mathrm{cm}^{-1}$ and $6.67 \times 10^{-3} \mathrm{~S} \cdot \mathrm{cm}^{-1}$, respectively, and are 2 orders of magnitude higher than those corresponding to the "as-synthesized" POMPhos solid ( $\sigma=$ $2.13 \times 10^{-5} \mathrm{~S} \cdot \mathrm{cm}^{-1}$ and $1.17 \times 10^{-4} \mathrm{~S} \cdot \mathrm{cm}^{-1}$, at the respective temperatures). To the best of our knowledge, these values represent the highest reported for this kind of POM materials. This increase in conductivity with respect to the "as synthesized" POMPhos material indicates the formation of more extended proton transfer pathways. However, the limited resolution of the crystallographic data precludes full description of such pathways. In addition, $\mathrm{N}_{2}$ adsorption/ desorption isotherms indicate that upon heating at $310{ }^{\circ} \mathrm{C}$ the solid transforms from a nonporous $\left(S_{\mathrm{BET}}=4.1 \mathrm{~m}^{2} / \mathrm{g}\right)$ to a mesoporous material $\left(S_{\mathrm{BET}}=54.8 \mathrm{~m}^{2} / \mathrm{g}\right)$, which can be attributed to the presence of the amorphous component $(\sim$ $30 \%)$. This compound appears to show water adsorption capability, and therefore, a contribution to the total proton conductivity from external surface cannot be ruled out.

This increase in conductivity with respect to the "as synthesized" POMPhos material is arguably attributed to higher mobility of protons due to the presence of hydronium ions, pointing to the presence of more extended proton transfer pathways. Significantly, the conductivity obtained for the POMPhos material is even higher than that reported for $\mathrm{H}_{3} \mathrm{PMo}_{12} \mathrm{O}_{40} \cdot 23 \mathrm{H}_{2} \mathrm{O}{ }^{67}$ In any case, the conductivity of the calcined material is within the highest values attained for zerodimensional polyoxometalates (POMs), although slightly higher conductivities have been reported for POM-based compounds, most of them showing low crystallinity and/or condensed phases. ${ }^{31,68}$

Catalytic Tests. Following our general interest in the development of various homogeneous catalytic processes that operate under mild conditions, ${ }^{71-73}$ herein we investigated a Mo-catalyzed reduction of diphenyl sulfoxide to diphenyl sulfide as a model reaction at $60^{\circ} \mathrm{C}$ in the presence of pinacol as a typical reducing agent (Scheme 1$)$. Initially, two different reaction temperatures $\left(60\right.$ and $85{ }^{\circ} \mathrm{C}$ ) and several solvents were tested including tetrahydrofuran, toluene, and acetonitrile 
(a)

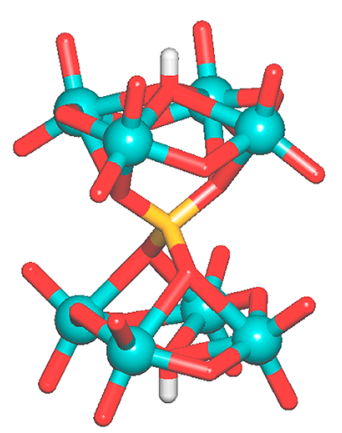

(c)

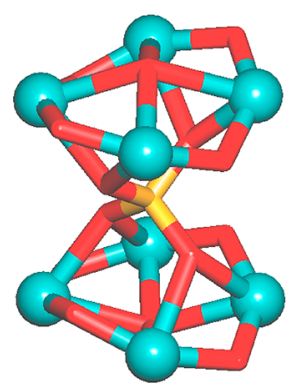

(b)

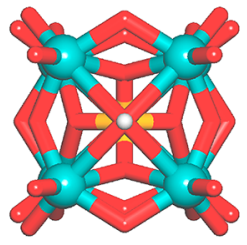

(d)

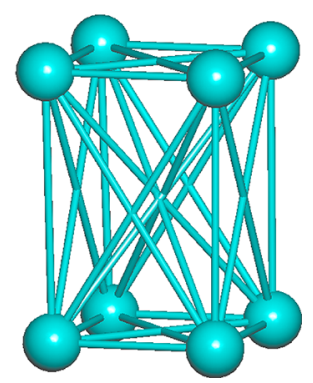

Figure 4. Structural fragments of POMPhos. (a) Front and (b) top views of the molecular $\mathrm{Mo}_{8}$ unit and (c) its simplified representation (terminal oxo ligands and $\mathrm{H}$ atoms are omitted). (d) Simplified graph representation of the $\left[\left\{\mathrm{Mo}_{4}\left(\mu_{4}-\mathrm{O}\right)(\mu-\mathrm{O})_{4}\right\}_{2}\left(\mu_{8}-\mathrm{PO}_{4}\right)\right]$ core showing a uninodal 7-connected net with the 7M8-1 topology and point symbol of $\left(3^{21}\right)$. Color codes: Mo (turquoise spheres), O (red), P (orange), and $\mathrm{H}$ (gray).

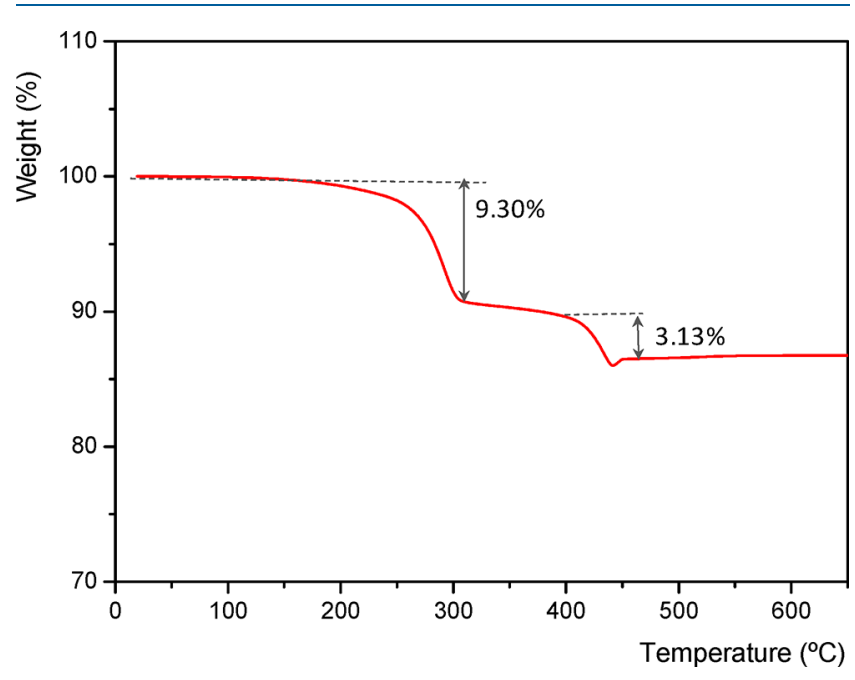

Figure 5. TG curve for POMPhos.

as the most promising options on account of previous studies. $^{21,23,26}$ The obtained results are summarized in Table 2.

For an initial selection of the solvents tested (Table 2), higher product yields can be obtained when prolonging the reaction time from 24 to $48 \mathrm{~h}$. After $48 \mathrm{~h}$ of the reaction, the maximum yields attained are $52.7 \%$ (THF, entry 2), $68.0 \%$ $\left(\mathrm{CH}_{3} \mathrm{CN}\right.$, entry 4$)$, and $94.3 \%$ (toluene, entry 7$)$. To optimize the reaction conditions for acetonitrile as a preferable solvent, we attempted further extension of the reaction time up to $72 \mathrm{~h}$ which resulted in a $97.7 \%$ yield of diphenyl sulfide (entry 5).

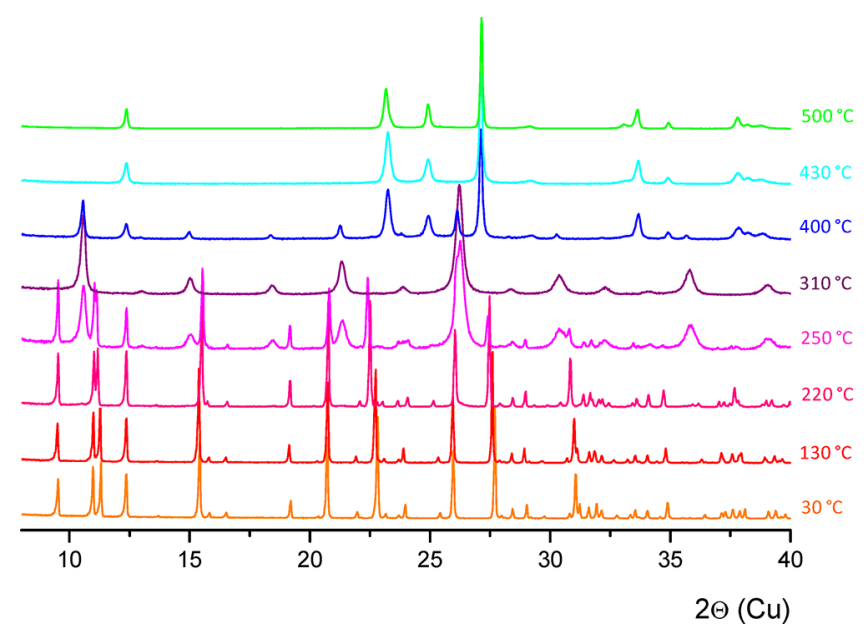

Figure 6. Thermodiffractometric study for POMPhos.

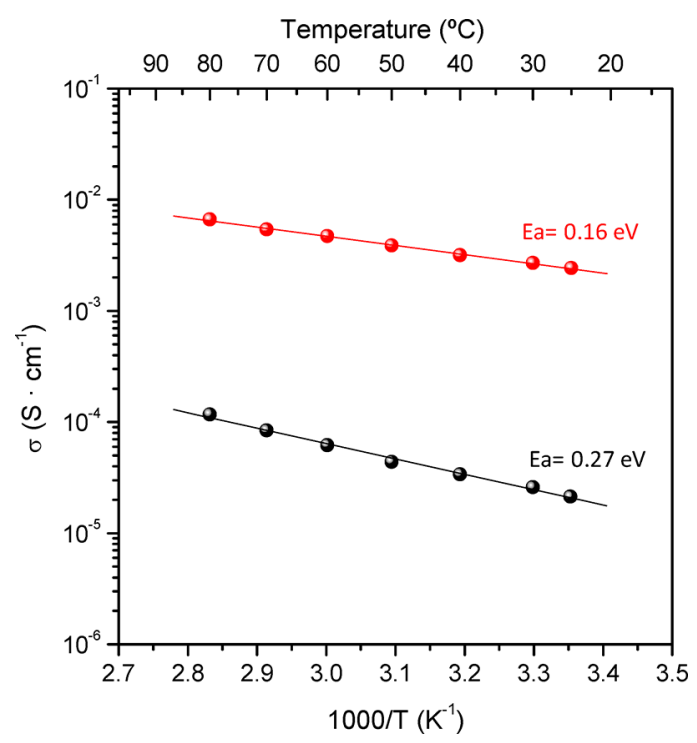

Figure 7. Arrhenius plot of total conductivity versus reciprocal temperature for POMPhos (black) and the $310^{\circ} \mathrm{C}$ calcined sample (red) at $95 \%$ of relative humidity $(\mathrm{RH}) . E_{\mathrm{a}}$ values are highlighted.

Scheme 1. Reduction of Diphenyl Sulfoxide to Diphenyl Sulfide with the POMPhos/Pinacol System

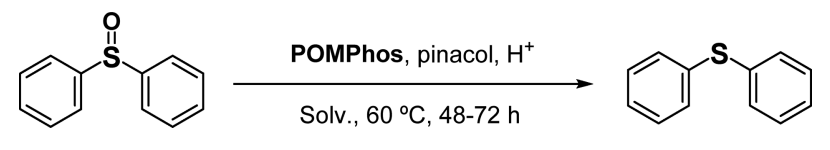

The use of acetonitrile as a solvent is also crucial to avoid the formation of diphenyl sulfone as a byproduct. ${ }^{69,70}$ In fact, the formation of diphenyl sulfone does not exceed $0.5 \%$ in the system with $\mathrm{CH}_{3} \mathrm{CN}$ as a solvent, while being appreciably higher in the systems operating in THF (up to 28\%) and toluene (up to 5.5\%). For the system in $\mathrm{CH}_{3} \mathrm{CN}$, an increase of the reaction temperature from 60 to $85{ }^{\circ} \mathrm{C}$ (refluxing conditions) is not favorable for the formation of diphenyl sulfide (Table 2, entries 8-10). Aiming at a potential application of more environmentally friendly solvents ${ }^{74}$ than toluene or acetonitrile, we also carried out the reduction of diphenyl sulfoxide in ethanol, isopropanol, 1-butanol, and methanol (Table 2, entries 11-14). All these solvents appear to be inferior than toluene and acetonitrile due to the lower 
Table 2. Reduction of Diphenyl Sulfoxide to Diphenyl Sulfide with the POMPhos/Pinacol System ${ }^{a}$

$\begin{array}{cclccc}\text { entry } & \begin{array}{c}\text { reducing } \\ \text { agent }\end{array} & \text { solvent } & \begin{array}{c}\text { temperature } \\ \left({ }^{\circ} \mathrm{C}\right)\end{array} & \begin{array}{c}\text { time } \\ (\mathrm{h})\end{array} & \begin{array}{c}\text { yield of diphenyl } \\ \text { sulfide }(\%)^{b}\end{array} \\ 1 & \text { pinacol } & \text { THF } & 60 & 24 & 52.0^{c} \\ 2 & \text { pinacol } & \text { THF } & 60 & 48 & 52.7^{d} \\ 3 & \text { pinacol } & \mathrm{CH}_{3} \mathrm{CN} & 60 & 24 & 31.1 \\ 4 & \text { pinacol } & \mathrm{CH}_{3} \mathrm{CN} & 60 & 48 & 68.0 \\ 5 & \text { pinacol } & \mathrm{CH}_{3} \mathrm{CN} & 60 & 72 & 97.7 \\ 6 & \text { pinacol } & \text { toluene } & 60 & 24 & 90.3^{e} \\ 7 & \text { pinacol } & \text { toluene } & 60 & 48 & 94.3^{f} \\ 8 & \text { pinacol } & \mathrm{CH}_{3} \mathrm{CN} & 85 & 24 & 7.4 \\ 9 & \text { pinacol } & \mathrm{CH}_{3} \mathrm{CN} & 85 & 48 & 19.1 \\ 10 & \text { pinacol } & \mathrm{CH}_{3} \mathrm{CN} & 85 & 72 & 75.4 \\ 11 & \text { pinacol } & \text { EtOH } & 60 & 24 & 52.0^{g} \\ 12 & \text { pinacol } & 2-\text {-propanol } & 60 & 24 & 6.8^{h} \\ 13 & \text { pinacol } & 1-\text { butanol } & 60 & 24 & 65.8^{i} \\ 14 & \text { pinacol } & \mathrm{CH}_{3} \mathrm{OH} & 60 & 24 & 42.6^{j} \\ 15 & \text { pinacol } & \text { ZBE-2000 } & 60 & 24 & 4.1\end{array}$

${ }^{a}$ Reaction conditions: POMPhos catalyst $(5 \mu \mathrm{mol}), \mathrm{HCl}$ promoter $(0.1 \mathrm{mmol})$, substrate $(0.25 \mathrm{mmol})$, pinacol $(0.25 \mathrm{mmol})$, and solvent (up to $5 \mathrm{~mL}$ total volume). ${ }^{b}$ Yield of diphenyl sulfide [(moles of product/mol of substrate $) \times 100] .{ }^{c-j}$ Herein, diphenyl sulfone is also formed as a byproduct. ${ }^{c} 11.3 \% .{ }^{d} 28.7 \%$. ${ }^{e} 5.5 \% .{ }_{2.5 \%}{ }^{g} 0.3 \%$. ${ }^{h} 0.7 \%$. ${ }^{i} 0.5 \%$. ${ }^{j} 2.2 \%$. ${ }^{k}$ Ionic liquid (1-ethyl-3-methylimidazolium triflate).

solubility of the catalyst, although reasonable product yields can be obtained in 1-butanol (65.8\%) and ethanol (52.0\%). A reaction performed in an ionic liquid (1-ethyl-3-methylimidazolium triflate) resulted in a very low product yield of $4.1 \%$ (Table 2, entry 15).

Additionally, the effect of an acid promoter $(\mathrm{HCl})$ was investigated for the system operating at $60{ }^{\circ} \mathrm{C}$ in $\mathrm{CH}_{3} \mathrm{CN}$ (Figure 8), highlighting a clear need of a slightly acidic

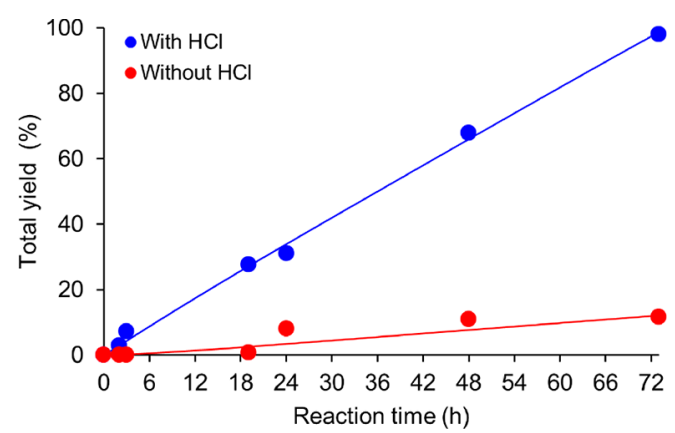

Figure 8. Effect of $\mathrm{HCl}$ as acid promoter on the product accumulation (diphenyl sulfide) in the reduction of diphenyl sulfoxide with the POMPhos/pinacol system. Reaction conditions: POMPhos catalyst (5 $\mu \mathrm{mol}$ ), $\mathrm{HCl}$ promoter (optional, $0.1 \mathrm{mmol}$ ), substrate $(0.25$ $\mathrm{mmol}$ ), pinacol $(0.25 \mathrm{mmol}), \mathrm{CH}_{3} \mathrm{CN}$ (up to $5 \mathrm{~mL}$ total volume), and $60{ }^{\circ} \mathrm{C}$.

medium to achieve high yield of diphenyl sulfide generation. The tests without an acid promoter in different solvents were also performed, revealing low product yields (Table S1, Supporting Information).

We also evaluated several types of reducing agents (Table 3, Figure S9), with an emphasis on the application of low-cost, biodegradable, and environmentally friendly reducing agents (i.e., pinacol and ethylene glycol) to the detriment of those commonly used in such reduction processes (i.e., triphenylphosphine, phenylsilane). Surprisingly, the use of pinacol leads
Table 3. POMPhos-Catalyzed Reduction of Diphenyl Sulfoxide to Diphenyl Sulfide in the Presence of Different Reducing Agents ${ }^{a}$

$\begin{array}{cllcc}\text { entry } & \text { reducing agent } & \text { solvent } & \begin{array}{c}\text { time } \\ (\mathrm{h})\end{array} & \begin{array}{c}\text { yield of diphenyl sulfide } \\ (\%)^{b}\end{array} \\ 1 & \text { pinacol } & \text { THF } & 24 & 52.0^{c} \\ 2 & \text { pinacol } & \text { THF } & 48 & 52.7^{d} \\ 3 & \text { ethylene glycol } & \text { THF } & 24 & 2.8 \\ 4 & \text { ethylene glycol } & \text { THF } & 48 & 4.4 \\ 5 & \text { triphenylphosphine } & \text { THF } & 24 & 79.9 \\ 6 & \text { triphenylphosphine } & \text { THF } & 48 & 85.4 \\ 7 & \text { phenylsilane } & \text { THF } & 24 & 57.3^{e} \\ 8 & \text { phenylsilane } & \text { THF } & 48 & 46.7^{f} \\ 9 & \text { pinacol } & \text { toluene } & 24 & 90.3^{g} \\ 10 & \text { pinacol } & \text { toluene } & 48 & 94.3^{h} \\ 11 & \text { triphenylphosphine } & \text { toluene } & 24 & 77.7 \\ 12 & \text { triphenylphosphine } & \text { toluene } & 48 & 80.1 \\ 13 & \text { pinacol } & \mathrm{CH}_{3} \mathrm{CN} & 24 & 31.1 \\ 14 & \text { pinacol } & \mathrm{CH}_{3} \mathrm{CN} & 48 & 68.0 \\ 15 & \text { triphenylphosphine } & \mathrm{CH}_{3} \mathrm{CN} & 24 & 87.1 \\ 16 & \text { triphenylphosphine } & \mathrm{CH}_{3} \mathrm{CN} & 48 & 88.4\end{array}$

${ }^{a}$ Reaction conditions: POMPhos catalyst $(5 \mu \mathrm{mol}), \mathrm{HCl}$ promoter $(0.1 \mathrm{mmol})$, substrate $(0.25 \mathrm{mmol})$, reducing agent $(0.25 \mathrm{mmol})$, solvent (up to $5 \mathrm{~mL}$ total volume), $60{ }^{\circ} \mathrm{C}$. ${ }^{b}$ Yield of diphenyl sulfide [(moles of product $/ \mathrm{mol}$ of substrate $) \times 100 \%] .{ }^{c-h}$ Herein, diphenyl sulfone is also formed as a byproduct. ${ }^{c} 11.3 \% .{ }^{d} 28.7 \%$. ${ }^{e} 4.6 \% .{ }^{f} 7.8 \%$, $g_{5.5 \%}{ }^{h} 2.5 \%$.

to results from very good to excellent, depending on the solvent used. Thus, for the POMPhos/pinacol system (Table 3 ), the obtained yields of diphenyl sulfide ( $52.7 \%$ in THF, entry 2; $94.3 \%$ in toluene, entry $10 ; 68.0 \%$ in $\mathrm{CH}_{3} \mathrm{CN}$, entry 14) are comparable or even better in some cases than those when using triphenylphosphine as a standard reducing agent ( $85.4 \%$ in THF, entry $6 ; 80.1 \%$ in toluene, entry $12 ; 88.4 \%$ in $\mathrm{CH}_{3} \mathrm{CN}$, entry 16). Low yields of diphenyl sulfide were achieved only when ethylene glycol was used as a reducing agent (Table 3, entries 3 and 4). The application of phenylsilane as a popular reducing agent led to the $57.3 \%$ product yield (entry 7). In this case, competing formation of diphenyl sulfone was also observed, which explains a slight decrease in the product yield after a prolonged reaction time (Table 3, entries 7 and 8). Because phenylsilane is also a highly polluting chemical, pinacol was selected in the present study as an optional reducing agent to investigate the effects of different reaction parameters.

We also studied the effect of catalyst loading (Table 4 and Figure 9). In toluene at $60^{\circ} \mathrm{C}$, the product yield increases from 2.7 to $90.4 \%$ on growing the catalyst amount from 1 to $5 \mu \mathrm{mol}$. Such a high product yield can be achieved after $6 \mathrm{~h}$ of the reduction reaction, thus indicating that higher catalyst loadings accelerate the process (Table 4 , entries $1-3$ ). On the other side, low catalyst loading $(1 \mu \mathrm{mol})$ results only in a very low yield, thus justifying the need for a Mo catalyst in the present reduction systems.

A related behavior is observed when using acetonitrile as a solvent (maximum product yield grows from 8.7 to $88.2 \%$ on increasing the catalyst amount; entries 5-9), although requiring more prolonged reaction time in comparison with that in toluene. We attempted even further prolonging of the reaction time up to $72 \mathrm{~h}$, which resulted in up to $98.9 \%$ yield of diphenyl sulfide when using the POMPhos/pinacol system in acetonitrile. In fact, the reaction rates steadily grow on 
Table 4. Reduction of Diphenyl Sulfoxide to Diphenyl Sulfide with the POMPhos/Pinacol System Using Different Catalyst Loadings and Solvents ${ }^{a}$

\begin{tabular}{ccclcc} 
entry & $\begin{array}{c}\text { catalyst } \\
(\mu \text { mol })\end{array}$ & $\begin{array}{c}\text { reducing } \\
\text { agent }^{a}\end{array}$ & solvent & $\begin{array}{c}\text { time } \\
(\mathrm{h})\end{array}$ & $\begin{array}{c}\text { yield of diphenyl } \\
\text { sulfide }(\%)^{b}\end{array}$ \\
\hline 1 & 1 & pinacol & toluene & 6 & 2.7 \\
2 & 2.5 & pinacol & toluene & 6 & 64.4 \\
3 & 5 & pinacol & toluene & 6 & $90.4^{d}$ \\
4 & - & pinacol & THF & 48 & $<0.5$ \\
5 & 1 & pinacol & $\mathrm{CH}_{3} \mathrm{CN}$ & 6 & 2.7 \\
6 & 1 & pinacol & $\mathrm{CH}_{3} \mathrm{CN}$ & 48 & 8.7 \\
7 & 10 & pinacol & $\mathrm{CH}_{3} \mathrm{CN}$ & 6 & 13.7 \\
8 & 10 & pinacol & $\mathrm{CH}_{3} \mathrm{CN}$ & 48 & 88.2 \\
9 & 5 & pinacol & $\mathrm{CH}_{3} \mathrm{CN}$ & 48 & 68.0 \\
10 & 5 & pinacol & $\mathrm{CH}_{3} \mathrm{CN}$ & 48 & 12.6
\end{tabular}

${ }^{a}$ Reaction conditions: POMPhos catalyst $(1-10 \mu \mathrm{mol}), \mathrm{HCl}$ promoter $(0.1 \mathrm{mmol})$, substrate $(0.25 \mathrm{mmol})$, pinacol $(0.25 \mathrm{mmol})$, solvent (up to $5 \mathrm{~mL}$ total volume), and $60{ }^{\circ} \mathrm{C}$. ${ }^{b}$ Yield of diphenyl sulfide [(moles of product $/ \mathrm{mol}$ of substrate $) \times 100 \%]$. ${ }^{c}$ Without $\mathrm{HCl}$ promoter. ${ }^{d}$ Herein, diphenyl sulfone is also formed as a byproduct: $1.9 \%$.
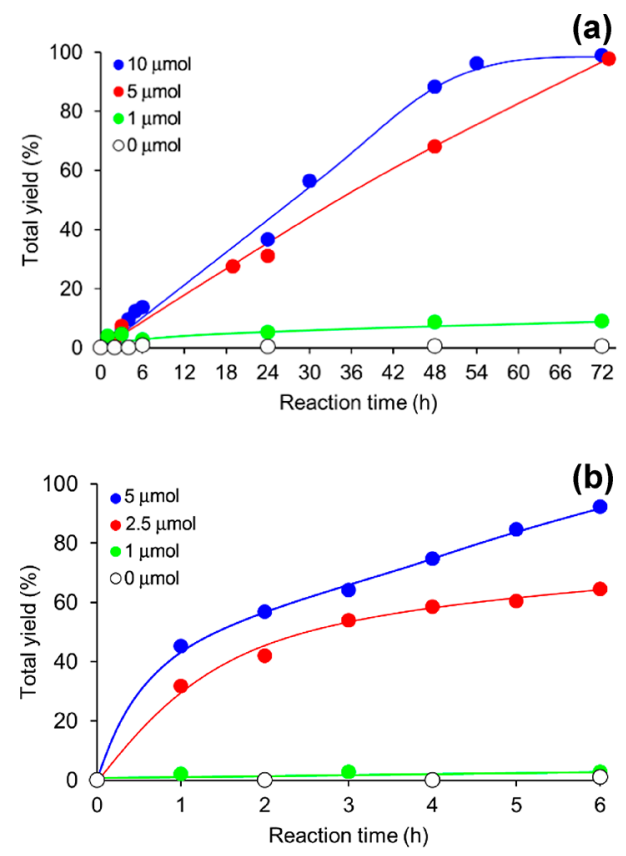

Figure 9. Effect of catalyst loading $(0,1,2.5,5$, and $10 \mu \mathrm{mol})$ on the yield of diphenyl sulfide in the reduction of diphenyl sulfoxide with the POMPhos/pinacol system in (a) acetonitrile and (b) toluene. Reaction conditions are those of Table 4.

increasing the catalyst loading (Figure 10). Despite a generally homogeneous nature of the present catalytic systems, at higher catalyst loadings the heterogeneous catalysis mode might also be present, which also depends on the type of solvent and the reaction conditions. It should also be highlighted, that the reduction of diphenyl sulfoxide does not occur to a considerable extent in the absence of the $\mathrm{HCl}$ promoter (12.6\% yield, entry 10$)$ or without the POMPhos catalyst ( $<0.5 \%$ yield, entry 4; Figure 9 or Table S1).

To explore the substrate scope of the present POMPhos/ pinacol system, we investigated the deoxygenation of other sulfoxides (i.e., methyl phenyl sulfoxide, dibenzyl sulfoxide, and dimethyl sulfoxide) apart from diphenyl sulfoxide as a model

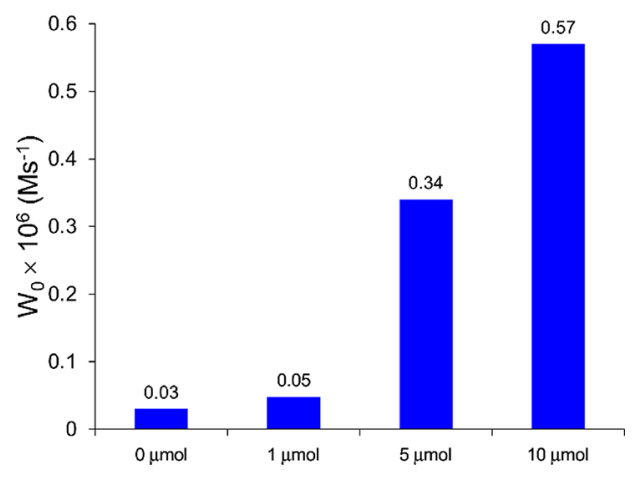

Figure 10. Initial reaction rate $\left(W_{0}\right)$ vs catalyst loading in the reduction of diphenyl sulfoxide with the POMPhos/pinacol system in acetonitrile. Reaction conditions are those of Table 4.

substrate (Table 5). Under optimized conditions, the same type of the POMPhos/pinacol system in toluene leads to

Table 5. Substrate Scope in the Reduction of Sulfoxides to Sulfides with the POMPhos/pinacol system in toluene ${ }^{a, b}$

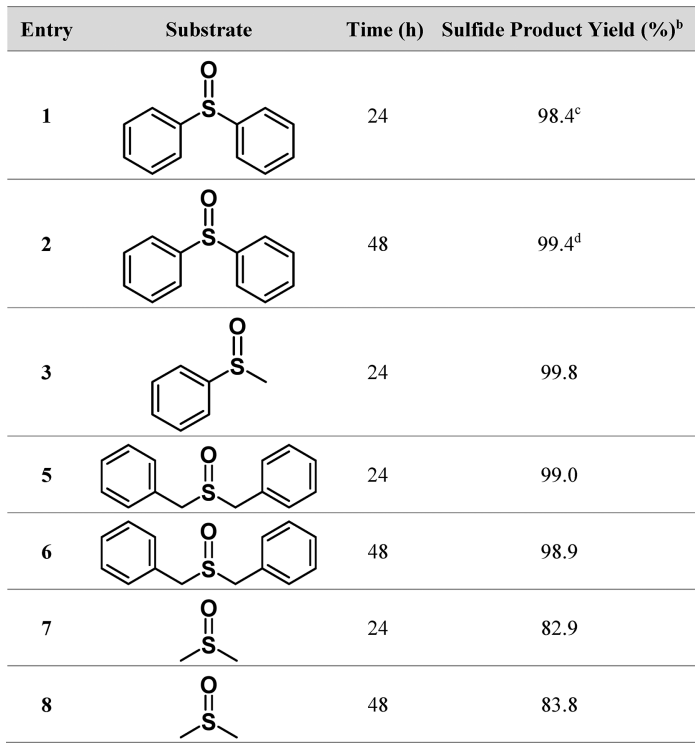

${ }^{a}$ Reaction conditions: POMPhos catalyst $(10 \mu \mathrm{mol}), \mathrm{HCl}$ promotor $(0.1 \mathrm{mmol})$, substrate $(0.25 \mathrm{mmol})$, pinacol $(0.25 \mathrm{mmol})$, toluene solvent (up to $2.5 \mathrm{~mL}$ total volume), and $60{ }^{\circ} \mathrm{C}$. ${ }^{b} \mathrm{Key}$ : (b) Yield of sulfide product [(moles of product $/ \mathrm{mol}$ of substrate $) \times 100 \%]$. (c) Herein, diphenyl sulfone is also formed as a byproduct: $0.7 \%$. (d) Herein, diphenyl sulfone is also formed as a byproduct: $0.6 \%$.

excellent yields of different sulfide products, namely diphenyl sulfide (98.4\%, entry 1), methyl phenyl sulfide (99.8\%, entry 3 ), dibenzyl sulfide (99.0\%, entry 5), and dimethyl sulfide (82.9\%, Table 5, entry 7). These data show a substrate versatility of the present catalytic system, wherein diaryl, alkylaryl, dibenzyl, and dialkyl sulfoxides with a different degree of bulkiness can be applied as suitable substrates. The effect of acid promoter is also crucial when using bulky substrates, as attested by low efficiency of the catalytic system in the absence of $\mathrm{HCl}$ (Table S2, Supporting Information). However, an interesting result was obtained in the reduction of dimethyl sulfoxide, wherein a good yield of dimethyl sulfide (73\%) was achieved without an acid promoter. 
To study a potential reuse of the POMPhos catalyst in more than one reaction cycle, we carried out the sequential additions of fresh diphenyl sulfoxide and pinacol to the reaction mixture under the optimized conditions and within $20 \mathrm{~h}$ periods (Figure 11). The reaction was monitored by GC, showing that

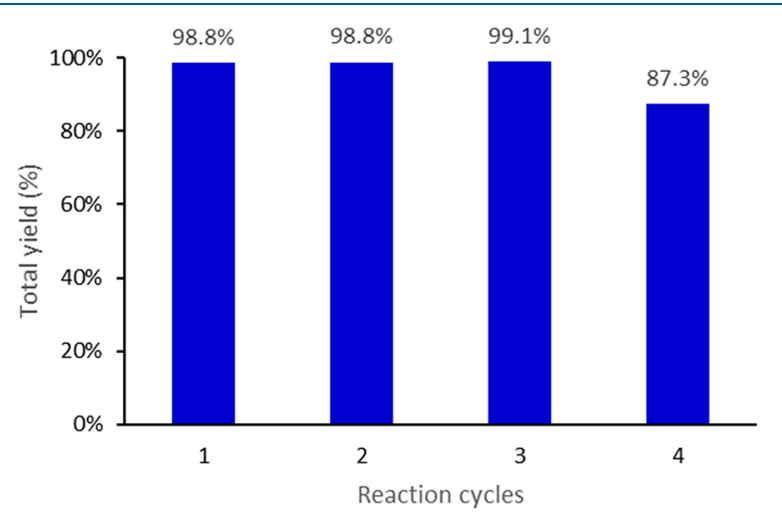

Figure 11. Catalytic activity POMPhos in the reduction of diphenyl sulfoxide to diphenyl sulfide after several reaction cycles. The reactions were carried out by successive addition of new portions of diphenyl sulfoxide and pinacol; yields were determined by GC. Conditions: POMPhos $(10 \mu \mathrm{mol}), \mathrm{HCl}$ promotor $(0.1 \mathrm{mmol})$, substrate $(0.25 \mathrm{mmol}$, added in each cycle), pinacol $(0.25 \mathrm{mmol}$, added in each cycle), toluene solvent (up to $2.5 \mathrm{~mL}$ total volume), 20 $\mathrm{h}$, and $60^{\circ} \mathrm{C}$.

the catalyst maintains an initial level of activity for at least three cycles (98.8-99.1\% product yields, Figure 11). A drop in product yield to $87.3 \%$ was observed after the fourth cycle. In a different assay, we attempted an isolation of the catalyst from the reaction mixture. The catalyst was precipitated, washed with $\mathrm{CH}_{2} \mathrm{Cl}_{2}$, dried, and subjected to a new catalytic test (conditions of Figure 11). This resulted in an almost original level of activity (94.1\% yield of diphenyl sulfide). Besides this, the IR spectrum of the recovered catalyst (Figure S11, Supporting Information) shows that the structure of POMPhos is maintained, although minor differences might be attributed to a lower purity of sample and presence of additional $\mathrm{OH}$ groups. A slightly inferior product yield can be explained by a small decrease of the catalyst loading after the recovery experiment.

Although the detailed investigation of the catalytic reaction mechanism was out of the scope of the present study, we can propose the following key steps in the POMPhos-catalyzed sulfoxide reduction on the basis of prior studies by Sanz and co-workers. $^{29,30,75}$ The activation of the catalyst would be achieved upon the reaction with an acid promoter, presumably resulting in the protonation of oxo and/or phosphate ligands to give an oxo/hydroxo molybdenum intermediate with coordinatively unsaturated metal centers. This would react with pinacol to form a pinacolate ligand containing $\mathrm{Mo}(\mathrm{VI})$ complex with a release of $\mathrm{H}_{2} \mathrm{O}$ molecule. The pinacolate ligand then would be oxidatively cleaved by the Mo(VI) center, resulting in the formation of a free acetone molecule and an oxomolybdenum(IV) intermediate containing a weakly coordinated acetone ligand. ${ }^{29,30}$ This ligand would quickly undergo an exchange reaction with the sulfoxide substrate, forming a free acetone molecule and the next oxo Mo(IV) intermediate with coordinated sulfoxide. This intermediate would then release the sulfide product with a regeneration of dioxo $\mathrm{Mo}(\mathrm{VI})$ catalyst. $^{29}$ Possible transformation of $\mathrm{Mo}(\mathrm{VI})$ to
Mo(IV) species can be monitored by a typical color change of the reaction mixture from white to pale blue, respectively. ${ }^{76}$ Besides, to prove a key role of pinacol as a reducing agent, we tested the effect of its loading on the activity of POMPhos in the reduction of diphenyl sulfoxide in $\mathrm{CH}_{3} \mathrm{CN}$ medium (Figure S10, Supporting Information). In fact, the use of only 0.5 equiv of pinacol relative to the sulfoxide substrate leads to a low yield of sulfide product (36.5\% after $24 \mathrm{~h}$ ). However, an equimolar loading of pinacol relative to the substrate results in a high product yield of $89.5 \%$ after $24 \mathrm{~h}$ (Figure S10). The sulfide product yields can grow up to $99 \%$ on further increasing the pinacol loading up to 2 equiv relative to the substrate. These results confirm the need for at least 1 equiv of pinacol in the present Mo-catalyzed systems for sulfoxide reduction.

\section{CONCLUSIONS}

In summary, we have assembled and fully characterized a new $\mathrm{Mo}_{8}$ cluster that is driven by the $\mu_{4}-\mathrm{OH}^{-}$and $\mu_{8}-\mathrm{PO}_{4}{ }^{3-}$ spacers. The obtained compound features an intricate structure that has been topologically classified as a uninodal 7-connected net with the 7M8-1 topology. We have demonstrated that this $\mathrm{Mo}_{8}$ derivative acts as an efficient homogeneous catalyst for the reduction of diphenyl sulfoxide to diphenyl sulfide, which has been investigated in detail as a model reaction. In this reaction, pinacol can be used as a low-cost, environmentally friendly, and highly efficient reducing agent. The effects of different reaction parameters such as the type of solvent, reducing agent, and reaction time and temperature, as well as the catalyst loading, have been investigated, leading to 94-99\% yields of diphenyl sulfide under optimized conditions. Besides this, we showed that the substrate scope of the present Mobased catalytic system for sulfoxide reduction can be extended to the examples of diaryl, alkylaryl, dibenzyl, and dialkyl sulfoxides with excellent product yields obtained. Further research on probing the catalytic activity of Mo-based systems in other catalytic transformations will be pursued. ${ }^{77}$ We have also demonstrated that the polyoxometalate derivative obtained by heating the "as-synthesized" POMPhos at 310 ${ }^{\circ} \mathrm{C}$ exhibits a very high proton conductivity value $\left(6.67 \times 10^{-3}\right.$ $\mathrm{S} \cdot \mathrm{cm}^{-1}$ at $80^{\circ} \mathrm{C}$ and $\left.95 \% \mathrm{RH}\right)$ as consequence of the presence of ammonium ions, which favor the proton transfer through a Grotthuss-type mechanism.

\section{ASSOCIATED CONTENT}

\section{Supporting Information}

The Supporting Information is available free of charge on the ACS Publications website at DOI: 10.1021/acs.inorgchem.9b01376.

Additional physicochemical characterization, proton conductivity, and catalytic results and some crystallographic data for POMPhos (PDF)

\section{Accession Codes}

CCDC 1900362 contains the supplementary crystallographic data for this paper. These data can be obtained free of charge via www.ccdc.cam.ac.uk/data_request/cif, or by emailing data_request@ccdc.cam.ac.uk, or by contacting The Cambridge Crystallographic Data Centre, 12 Union Road, Cambridge CB2 1EZ, UK; fax: +44 1223336033. 


\section{AUTHOR INFORMATION}

\section{Corresponding Authors}

*E-mail: demadis@uoc.gr (K.D.D.).

*E-mail: kirillov@tecnico.ulisboa.pt (A.M.K.).

\section{ORCID}

Gellert Mezei: 0000-0002-3120-3084

Aurelio Cabeza: 0000-0002-1582-3240

Konstantinos D. Demadis: 0000-0002-0937-8769

\section{Author Contributions}

The manuscript was written through contributions of all authors. All authors have given approval to the final version of the manuscript.

\section{Funding}

K.D.D. acknowledges the Research Committee of the University of Crete (Grant KA 10329) for financial support. G.M. acknowledges the US National Science Foundation (Grant No. CHE-1808554) for support. A.M.K acknowledges the Foundation for Science and Technology (FCT) and Portugal 2020 (Projects UID/QUI/00100/2013 and LISBOA01-0145-FEDER-029697) for support. The publication was also prepared with the support of the RUDN University Program 5-100. T.A.F. acknowledges the FCT for BPD Grant SFRH/BPD/119980/2016. The work at the University of Malaga was funded by the Spanish MINECO Project MAT2016-77648-R and by Junta de Andalucia (Spain) P12FQM-1656 and FQM-113.

\section{Notes}

The authors declare no competing financial interest.

\section{ABBREVIATIONS}

POMs = polyoxometalates; $\mathrm{DI}=$ deionized water $\mathrm{BPMGLY}=$ bis(phosphonomethyl)glycine; HPAA $=R, S$-hydroxyphosphonoacetic acid; HEDP = hydroxyethyledine-1,1-diphosphonic acid; $\mathrm{PPA}=$ phenylphosphonic acid; $\mathrm{AMP}=$ aminotris(methylene phosphonic acid); EDPA $=1,2$-ethylenediphosphonic acid

\section{REFERENCES}

(1) Metal Phosphonate Chemistry: From Synthesis to Applications; Clearfield, A., Demadis, K. D., Eds.; Royal Society of Chemistry: London, 2012.

(2) Bogdan, Cs.; Peczely, G.; Gaizer, F. Protonation constants of ethane and propane frame-substituted oligophosphonic and oligophosphonocarboxylic acids. Polyhedron 2001, 20, 1809-1813.

(3) Dyer, S. J.; Anderson, C. E.; Graham, G. M. Thermal stability of amine methyl phosphonate scale inhibitors. J. Pet. Sci. Eng. 2004, 43, 259-270.

(4) Popov, K.; Rönkkömäki, H.; Lajunen, L. H. J. Critical evaluation of stability constants of phosphonic acids. Pure Appl. Chem. 2001, 73, $1641-1677$.

(5) Zorlu, Y.; Erbahar, D.; Çetinkaya, A.; Bulut, A.; Erkal, T. S.; Yazaydin, A. O.; Beckmann, J.; Yücesan, G. A cobalt arylphosphonate MOF - superior stability, sorption and magnetism. Chem. Commun. 2019, 55, 3053-3056.

(6) Murugavel, R.; Choudhury, A.; Walawalkar, M. G.; Pothiraja, R.; Rao, C. N. R. Metal complexes of organophosphate esters and openframework metal phosphates: Synthesis, structure, transformations, and applications. Chem. Rev. 2008, 108, 3549-3655.

(7) Demadis, K. D.; Ketsetzi, A. Degradation of phosphonate-based scale inhibitor additives in the presence of oxidizing biocides: "Collateral damages" in industrial water systems. Sep. Sci. Technol. 2007, 42, 1639-1649.

(8) Demadis, K. D. Chemistry of organophosphonate scale inhibitors. Part 4: Stability of amino-tris(methylenephosphonate) towards degradation by oxidizing biocides. Phosphorus, Sulfur Silicon Relat. Elem. 2006, 181, 167-176.

(9) Appelman, E. H.; Jache, A. W.; Muntean, J. V. The vanadium $(\mathrm{V})$-catalyzed oxidation of (1-hydroxyethylidene) bisphosphonic acid, $\mathrm{CH}_{3}(\mathrm{OH})\left(\mathrm{PO}_{3} \mathrm{H}_{2}\right)_{2}$ by hydrogen peroxide in aqueous solution. J. Mol. Catal. A: Chem. 1996, 106, 197-209.

(10) Hoffmann, T.; Friedel, P.; Harnisch, C.; Häußler, L.; Pospiech, D. Investigation of thermal decomposition of phosphonic acids. J. Anal. Appl. Pyrolysis 2012, 96, 43-53.

(11) Karl, D. M.; Beversdorf, L.; Björkman, K. M.; Church, M. J.; Martinez, A.; Delong, E. F. Aerobic production of methane in the sea. Nat. Geosci. 2008, 1, 473-478.

(12) Obojska, A.; Lejczak, B.; Kubrak, M. Degradation of phosphonates by streptomycete isolates. Appl. Microbiol. Biotechnol. 1999, 51, 872-876.

(13) Turhanen, P. A.; Vepsäläinen, J. J. Unexpected degradation of the bisphosphonate P-C-P bridge under mild conditions. Beilstein J. Org. Chem. 2008, 4, 7.

(14) Bauer, S.; Müller, H.; Bein, T.; Stock, N. Synthesis and characterization of the open-framework barium bisphosphonate $\left[\mathrm{Ba}_{3}\left(\mathrm{O}_{3} \mathrm{PCH}_{2} \mathrm{NH}_{2} \mathrm{CH}_{2} \mathrm{PO}_{3}\right)_{2}\left(\mathrm{H}_{2} \mathrm{O}\right)_{4}\right] \cdot 3 \mathrm{H}_{2} \mathrm{O}$. Inorg. Chem. 2005, 44, 9464-9470.

(15) Chen, S.-P.; Huang, G.-X.; Li, M.; Pan, L.-L.; Yuan, Y.-X.; Yuan, L.-J. New in situ condensation reaction of amino diphosphonic acids: A series of bicyclic phosphonate derivatives and three novel water clusters. Cryst. Growth Des. 2008, 8, 2824-2833.

(16) Chen, S.-P.; Yuan, Y.-X.; Pan, L.-L.; Yuan, L.-J. Vertical interpenetration of $1 \mathrm{D}$ water column and $1 \mathrm{D}$ coordination polymer chain. J. Inorg. Organomet. Polym. Mater. 2008, 18, 384-390.

(17) Chatgilialoglu, C.; Asmus, K. D. Sulfur Centered Reactive Intermediates in Chemistry and Biology; NATO ASI Series; Plenum: New York, 1990.

(18) Arterburn, J. B.; Perry, M. C. Rhenium catalyzed sulfoxide reduction. Tetrahedron Lett. 1996, 37, 7941-7944.

(19) Abu-Omar, M. M.; Khan, S. I. Molecular rhenium(V) oxotransferases: Oxidation of thiols to disulfides with sulfoxides. The case of substrate-inhibited catalysis. Inorg. Chem. 1998, 37, 4979-4985.

(20) Arias, J.; Newlands, C. R.; Abu-Omar, M. M. Kinetics and mechanisms of catalytic oxygen atom transfer with oxorhenium(V) oxazoline complexes. Inorg. Chem. 2001, 40, 2185-2192.

(21) Fernandes, A. C.; Romão, C. C. A novel method for the reduction of sulfoxides and pyridine $\mathrm{N}$-oxides with the system silane/ $\mathrm{MoO}_{2} \mathrm{Cl}_{2}$. Tetrahedron 2006, 62, 9650-9654.

(22) Reis, P. M.; Costa, P. J.; Romão, C. C.; Fernandes, J. A.; Calhorda, M. J.; Royo, B. Hydrogen activation by high-valent oxomolybdenum(VI) and -rhenium(VII) and -(V) compounds. Dalton Trans. 2008, 1727-1733.

(23) Fernandes, A. C.; Fernandes, J. A.; Romão, C. C.; Veiros, L. F.; Calhorda, M. J. Highly efficient reduction of sulfoxides with the system borane/oxo-rhenium. Organometallics 2010, 29, 5517-5525.

(24) Hille, R.; Rétey, J.; Bartlewski-Hof, U.; Reichenbecher, W.; Schink, B. Mechanistic aspects of molybdenum-containing enzymes. FEMS Microbiol. Rev. 1998, 22, 489-501.

(25) Hille, R. The mononuclear molybdenum enzymes. Chem. Rev. 1996, 96, 2757-2816.

(26) Fernandes, A. C.; Romão, C. C. Reduction of sulfoxides with boranes catalyzed by $\mathrm{MoO}_{2} \mathrm{Cl}_{2}$. Tetrahedron Lett. 2007, 48, 91769179.

(27) Fernandes, T. A.; Fernandes, A. C. Dioxomolybdenum complexes as excellent catalysts for the deoxygenation of aryl ketones to aryl alkenes. ChemCatChem 2015, 7, 3503-3507.

(28) Sanz, R.; Escribano, J.; Pedrosa, M. R.; Aguado, R.; Arnáiz, F. J. Dioxomolybdenum(VI)-catalyzed reductive cyclization of nitroaromatics. Synthesis of carbazoles and indoles. Adv. Synth. Catal. 2007, 349, 713-718.

(29) García, N.; García-García, P.; Fernández-Rodríguez, M. A.; Rubio, R.; Pedrosa, M. R.; Arnáiz, F. J.; Sanz, R. Pinacol as a new green reducing agent: Molybdenum-catalyzed chemoselective reduc- 
tion of sulfoxides and nitroaromatics. Adv. Synth. Catal. 2012, 354, 321-327.

(30) Rubio-Presa, R.; Fernández-Rodríguez, M. A.; Pedrosa, M. R.; Arnáiz, F. J.; Sanz, R. Molybdenum-catalyzed deoxygenation of heteroaromatic $\mathrm{N}$-oxides and hydroxides using pinacol as reducing agent. Adv. Synth. Catal. 2017, 359, 1752-1757.

(31) Chand, S.; Elahi, S. M.; Pal, A.; Das, M. C. Metal-organic frameworks and other crystalline materials for ultrahigh superprotonic conductivities of $10^{-2} \mathrm{~S} \cdot \mathrm{cm}^{-1}$ or higher. Chem. - Eur. J. 2019, 25, 6259-6269.

(32) Liu, W.-J.; Dong, L.-Z.; Li, R.-H.; Chen, Y.-J.; Sun, S.-N.; Li, S.L.; Lan, Y.-Q. Different protonic species affecting proton conductivity in hollow spherelike polyoxometalates. ACS Appl. Mater. Interfaces 2019, 11, 7030-7036.

(33) Niinomi, K.; Miyazawa, S.; Hibino, M.; Mizuno, N.; Uchida, S. High proton conduction in crystalline composites based on Preysslertype polyoxometalates and polymers under nonhumidified or humidified conditions. Inorg. Chem. 2017, 56, 15187-15193.

(34) Li, Z.; Lin, L.-D.; Zhao, D.; Sun, Y.-Q.; Zheng, S.-T. A series of unprecedented linear mixed-metal-substituted polyoxometalate trimers: Syntheses, structures, luminescence, and proton conductivity properties. Eur. J. Inorg. Chem. 2019, 2019, 437-441.

(35) Mao, J.-G.; Wang, Z.; Clearfield, A. Hydrothermal synthesis, characterization and crystal structures of two new zinc(II) phosphonates: $\mathrm{Zn}_{2}\left[\left(\mathrm{O}_{3} \mathrm{PCH}_{2}\right)_{2} \mathrm{NHCH}_{2} \mathrm{CO}_{2}\right]$ and $\mathrm{Zn}_{2}\left[\mathrm{HO}_{3} \mathrm{PCH}_{2} \mathrm{NH}\left(\mathrm{CH}_{2} \mathrm{PO}_{3}\right)_{2}\right]$. New J. Chem. 2002, 26, 1010-1014.

(36) APEX2 v2014.9-0; Bruker AXS Inc.: Madison, WI, 2014.

(37) De La Torre, A. G.; Bruque, S.; Aranda, M. A. G. Rietveld quantitative amorphous content analysis. J. Appl. Crystallogr. 2001, 34, 196-202.

(38) Rietveld, H. M. A profile refinement method for nuclear and magnetic structures. J. Appl. Crystallogr. 1969, 2, 65-71.

(39) Boeyens, J. C. A.; McDougal, G. J.; Smit, J. V. R. Crystallographic study of the ammonium/potassium 12-molybdophosphate ion-exchange system. J. Solid State Chem. 1976, 18, 191199.

(40) winDETA; Novocontrol GmbH: Hundsangen, Germany, 1995. (41) Blatov, V. A. Multipurpose crystallochemical analysis with the program package TOPOS. IUCr CompComm Newsletter 2006, 7, 438.

(42) Kostakis, G. E.; Blatov, V. A.; Proserpio, D. M. A method for topological analysis of high nuclearity coordination clusters and its application to Mn coordination compounds. Dalton Trans. 2012, 41, 4634-4640.

(43) Kostakis, G. E.; Perlepes, S. P.; Blatov, V. A.; Proserpio, D. M.; Powell, A. K. High-nuclearity cobalt coordination clusters: Synthetic, topological and magnetic aspects. Coord. Chem. Rev. 2012, 256, $1246-1278$.

(44) Packiam, D. E. J.; Vidyasagar, K. Syntheses and characterization of phosphonates and diphosphonates of molybdenum, $\mathrm{A}_{4}\left[\left(\mathrm{MoO}_{3}\right)_{5}\left(\mathrm{O}_{3} \mathrm{PR}\right)_{2}\right] \cdot \mathrm{xH}_{2} \mathrm{O}, \mathrm{A}_{2}\left[\mathrm{Mo}_{2} \mathrm{O}_{5}\left(\mathrm{O}_{3} \mathrm{PR}\right)_{2}\right]$ and $\mathrm{A}_{2}\left[\mathrm{Mo}_{2} \mathrm{O}_{5}\left(\mathrm{O}_{3} \mathrm{P}-\mathrm{R}-\mathrm{PO}_{3}\right)\right]\left(\mathrm{A}=\mathrm{K}, \mathrm{Rb}, \mathrm{Cs}, \mathrm{Tl}, \mathrm{NH}_{4}\right)$. Dalton Trans. 2017, 46, 16102-16112.

(45) Yang, L.; Zhou, Z.; Ma, P.; Wang, J.; Niu, J. Self-assembly of two ring-shaped hexanuclear $\mathrm{Mo}(\mathrm{VI})$ clusters. CrystEngComm 2013, $15,5452-5457$.

(46) Yang, L.; Ma, P.; Zhou, Z.; Wang, J.; Niu, J. A crown-shaped 24-molybdate cluster constructed by organotriphosphonate ligand. Inorg. Chem. 2013, 52, 8285-8287.

(47) Ma, P. T.; Zhang, X. Q.; Wang, J. P. Polyoxomolybdates functionalized with aminomethylene phosphonate. Russ. J. Coord. Chem. 2011, 37, 916-920.

(48) Huo, Y.; Chen, Y.-C.; Wu, S.-G.; Jia, J.-H.; Chen, W.-B.; Liu, J.L.; Tong, M.-L. pH-controlled assembly of organophosphonatebridged dysprosium(III) single-molecule magnets based on polyoxometalates. Inorg. Chem. 2018, 57, 6773-6777.

(49) Huo, Y.; Wan, R.; Ma, P.; Liu, J.-L.; Chen, Y.; Li, D.; Niu, J.; Wang, J.; Tong, M.-L. Organophosphonate-bridged polyoxometalate- based dysprosium(III) single-molecule magnet. Inorg. Chem. 2017, 56, 12687-12691.

(50) du Peloux, C.; Dolbecq, A.; Mialane, P.; Marrot, J.; Sécheresse, F. Template synthesis of $\left\{\left(\mathrm{Mov}_{2} \mathrm{O}_{4}\right)\left(\mathrm{O}_{3} \mathrm{PCH}_{2} \mathrm{PO}_{3}\right)\right\}_{\mathrm{n}}$ clusters $(\mathrm{n}=3$, 4, 10): Solid state and solution studies. Dalton Trans. 2004, 12591263.

(51) Dolbecq, A.; Compain, J.-D.; Mialane, P.; Marrot, J.; Sécheresse; Keita, F. B.; Holzle, L. R. B.; Miserque, F.; Nadjo, L. Hexa- and dodecanuclear polyoxomolybdate cyclic compounds: Application toward the facile synthesis of nanoparticles and film electrodeposition. Chem. - Eur. J. 2009, 15, 733-741.

(52) Tan, H.; Chen, W.; Liu, D.; Li, Y.; Wang, E. Two new cantilever-type polyoxometalates constructed from $\left\{\mathrm{Mo}_{2} \mathrm{O}_{4}\right\}^{2+}$ fragments and diphosphonates. Dalton Trans. 2010, 39, 1245-1249.

(53) Dumas, E.; Sassoye, C.; Smith, K. D.; Sevov, S. C. Synthesis and characterization of $\left[\mathrm{Mo}_{7} \mathrm{O}_{16}\left(\mathrm{O}_{3} \mathrm{PCH}_{2} \mathrm{PO}_{3}\right)_{3}\right]^{8-}:$ A mixed-valent polyoxomolybdenum diphosphonate anion with octahedrally and tetrahedrally coordinated molybdenum. Inorg. Chem. 2002, 41, 40294032.

(54) Calin, N.; Sevov, S. C. Novel mixed-valence heteropolyoxometalates: A molybdenum diphosphonate anion $\left[\mathrm{Mo}_{7}{ }_{7} \mathrm{Mo}^{\mathrm{VI}} \mathrm{O}_{16}\left(\mathrm{O}_{3} \mathrm{PPhPO}_{3} \mathrm{H}\right)_{4}\right]^{3-}$ and its one- and two-dimensional assemblies. Inorg. Chem. 2003, 42, 7304-7308.

(55) Wang, W.-N.; Li, J.; Sun, Z.-G.; Tong, F.; Zhu, Y.-Y.; Xu, L.; Gong, J. Solvothermal syntheses and structure of a new polyoxomolybdate functionalized with carboxyphosphonate. $Z$. Anorg. Allg. Chem. 2011, 637, 108-111.

(56) Li, X.-M.; Chen, Y.-G.; Su, C.; Zhou, S.; Tang, Q.; Shi, T. Functionalized pentamolybdodiphosphate-based inorganic-organic hybrids: Synthesis, structure, and properties. Inorg. Chem. 2013, 52, $11422-11427$.

(57) Ayi, A. A.; Burrows, A. D.; Mahon, M. F.; Sebestyen, V. M. A molybdenum diphosphonate network structure exhibiting reversible dehydration and selective uptake of methanol. CrystEngComm 2013, 15, 9301-9303.

(58) Nowack, B.; Stone, A. T. Degradation of nitrilotris(methylenephosphonic cid) and related (amino)phosphonate chelating agents in the presence of manganese and molecular oxygen. Environ. Sci. Technol. 2000, 34, 4759-4765.

(59) Nowack, B.; Stone, A. T. Manganese-catalyzed degradation of phosphonic acids. Environ. Chem. Lett. 2003, 1, 24-31.

(60) Kononova, S. V.; Nesmeyanova, M. A. Phosphonates and their degradation by microorganisms. Biochemistry (Moscow) 2002, 67, 184-195.

(61) Klinger, J.; Lang, M.; Sacher, F.; Brauch, H.-J.; Maier, D.; Worch, E. Formation of glyphosate and AMPA during ozonation of waters containing ethylenediaminetetra(methylenephosphonic acid). Ozone: Sci. Eng. 1998, 20, 99-110.

(62) Sillanpää, M. E. T.; Kurniawan, T. A.; Lo, W.-H. Degradation of chelating agents in aqueous solution using advanced oxidation process (AOP). Chemosphere 2011, 83, 1443-1460.

(63) Bai, Y.-C.; Liu, L.-P.; Yan, X.-J.; Chu, W.; Zhu, Y.-Y.; Song, Y.T.; Huang, R.-D. Three sandglass-type molybdophosphates obtained via a new route: Synthesis and characterization of $\mathrm{X}^{7}\left[\mathrm{PMo}_{8} \mathrm{O}_{30}\right](\mathrm{X}=$ $\left.\mathrm{Na}^{+}, \mathrm{K}^{+}, \mathrm{NH}_{4}^{+}\right)$. J. Solid State Chem. 2009, 182, 89-94.

(64) Ganapathy, S.; Fournier, M.; Paul, J. F.; Delevoye, L.; Guelton, M.; Amoureux, J. P. Location of protons in anhydrous Keggin heteropolyacids $\mathrm{H}_{3} \mathrm{PMo}_{12} \mathrm{O}_{40}$ and $\mathrm{H}_{3} \mathrm{PW}_{12} \mathrm{O}_{40}$ by ${ }^{1} \mathrm{H}\left\{{ }^{31} \mathrm{P}\right\} /{ }^{31} \mathrm{P}\left\{{ }^{1} \mathrm{H}\right\}$ REDOR NMR and DFT quantum chemical calculations. J. Am. Chem. Soc. 2002, 124, 7821-7828.

(65) Hu, J.; Burns, R. C. The effect of cation type and $\mathrm{H}^{+}$on the catalytic activity of the Keggin anion $\left[\mathrm{PMo}_{12} \mathrm{O}_{40}\right]^{3-}$ in the oxidative dehydrogenation of isobutyraldehyde. J. Catal. 2000, 195, 360-375.

(66) Colomban, P. Proton Conductors: Solids, Membranes and Gels Materials and Devices. Chemistry of Solid Materials; Cambridge University Press: Cambridge, U.K., 1992; Vol. 2.

(67) Nakamura, O.; Kodama, T.; Ogino, I.; Miyake, Y. PWA doped $\mathrm{SiO}_{2}$ PEG hybrid materials of Class II. Chem. Lett. 1979, 8, 17-18. 
(68) Ito, T.; Otobe, S.; Oda, T.; Kojima, T.; Ono, S.; Watanabe, M.; Kiyota, Y.; Misawa, T.; Koguchi, S.; Higuchi, M.; Kawano, M.; Nagase, Y. Polymerizable ionic liquid crystals comprising polyoxometalate clusters toward inorganic-organic hybrid solid electrolytes. Polymers 2017, 9, 290.

(69) Mitsudome, T.; Takahashi, Y.; Mizugaki, T.; Jitsukawa, K.; Kaneda, K. Hydrogenation of sulfoxides to sulfides under mild conditions using ruthenium nanoparticle catalysts. Angew. Chem., Int. Ed. 2014, 53, 8348-8351.

(70) Sun, X.; Haas, D.; Sayre, K.; Weller, D. Formation of diphenyl sulfoxide and diphenyl sulfide via the aluminum chloride-facilitated electrophilic aromatic substitution of benzene with thionyl chloride, and a novel reduction of sulfur (IV) to sulfur (II). Phosphorus, Sulfur Silicon Relat. Elem. 2010, 185, 2535-2542.

(71) Fernandes, T. A.; Santos, C. I. M.; André, V.; Kłak, J.; Kirillova, M. V.; Kirillov, A. M. Copper(II) coordination polymers selfassembled from aminoalcohols and pyromellitic acid: Highly active pre-catalysts for the mild water-promoted oxidation of alkanes. Inorg. Chem. 2016, 55, 125-135.

(72) Armakola, E.; Colodrero, R. M. P.; Bazaga-García, M.; Salcedo, I. R.; Choquesillo-Lazarte, D.; Cabeza, A.; Kirillova, M. V.; Kirillov, A. M.; Demadis, K. D. Three-component copper-phosphonate-auxiliary ligand systems: Proton conductors and efficient catalysts in mild oxidative functionalization of cycloalkanes. Inorg. Chem. 2018, 57, 10656-10666.

(73) Demadis, K. D.; Anagnostou, Z.; Panera, A.; Mezei, G.; Kirillova, M. V.; Kirillov, A. M. Three-component 1D and 2D metal phosphonates: structural variability, topological analysis and catalytic hydrocarboxylation of alkanes. RSC Adv. 2017, 7, 17788-17799.

(74) Byrne, F. P.; Jin, S.; Paggiola, G.; Petchey, T. H. M.; Clark, J. H.; Farmer, T. J.; Hunt, A. J.; McElroy, C. R.; Sherwood, J. Tools and techniques for solvent selection: Green solvent selection guides. Sustainable Chem. Processes 2016, 4, 7.

(75) García, N.; Rubio-Presa, R.; García-García, P.; FernándezRodríguez, M. A.; Pedrosa, M. R.; Arnáiz, F. J.; Sanz, R. A selective, efficient and environmentally friendly method for the oxidative cleavage of glycols. Green Chem. 2016, 18, 2335-2340.

(76) He, T.; Yao, J. Photochromism of molybdenum oxide. J. Photochem. Photobiol., C 2003, 4, 125-143.

(77) Sustainable Catalysis: Energy-Efficient Reactions and Applications; Luque, R.; Lam, F. L.-Y., Eds.;Wiley-VCH: Weinheim, Germany, 2018.

(78) winDETA; Novocontrol GmbH: Hundsangen, Germany, 1995. 